LBNL-48581

\title{
Energy Use and Power Levels in New Monitors and Personal Computers
}

\author{
Judy A. Roberson, Gregory K. Homan, \\ Akshay Mahajan, Bruce Nordman, \\ Carrie A. Webber, Richard E. Brown, \\ Marla McWhinney, and Jonathan G. Koomey \\ Energy Analysis Department \\ Environmental Energy Technologies Division \\ Ernest Orlando Lawrence Berkeley National Laboratory \\ University of California \\ Berkeley CA 94720, USA
}

July 2002

To download this paper and related data go to:

http://enduse.lbl.gov/Projects/OffEqpt.html

The work described in this paper was supported by the Office of Atmospheric Programs, Climate Protection Partnerships Division of the U.S. Environmental Protection Agency and prepared for the U.S. Department of Energy under Contract No. DE-AC03-76SF00098. 


\section{Table of Contents}

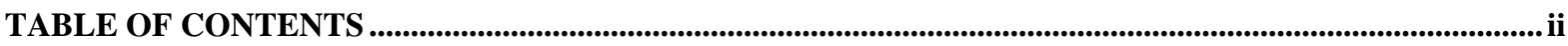

LIST OF TABLES, LIST OF FIGURES ..................................................................................................................... iii

ABBREVIATIONS AND ACRONYMS, ACKNOWLEDGEMENTS .......................................................................

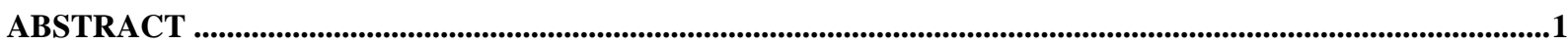

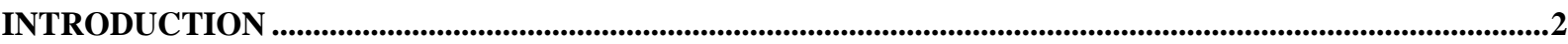

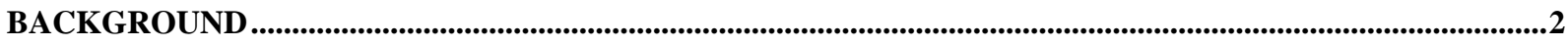

ESTIMATES OF SAVINGS FROM OFFICE EQUIPMENT POWER MANAGEMENT ............................................................

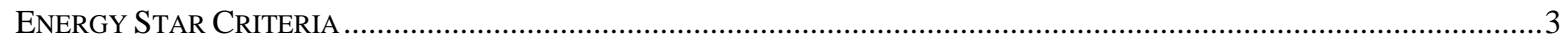

POWER MANAGEMENT: TECHNOLOGY …………………….................................................................

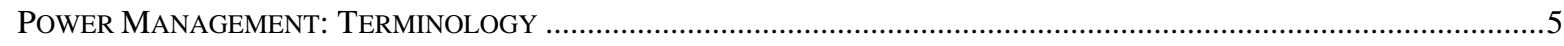

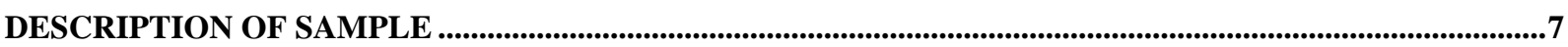

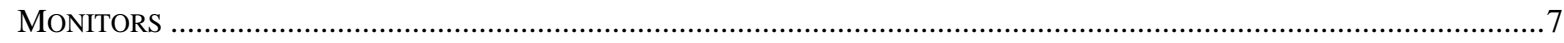

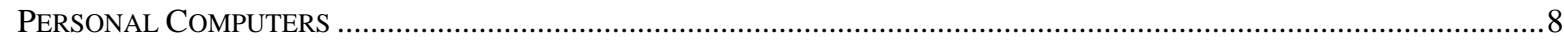

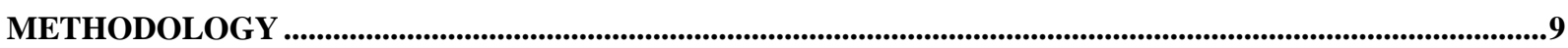

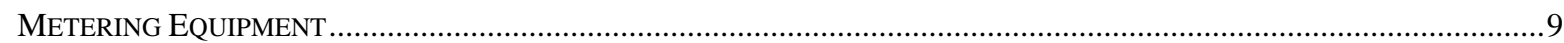

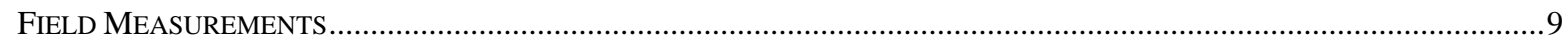

RESULTS AND DISCUSSION ..............................................................................................................................10

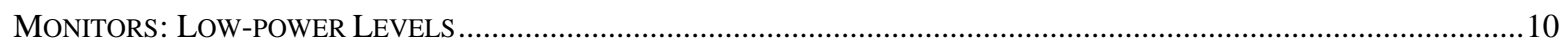

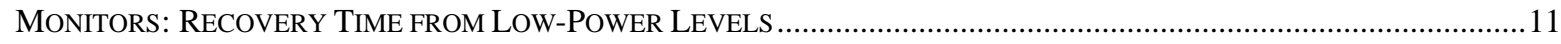

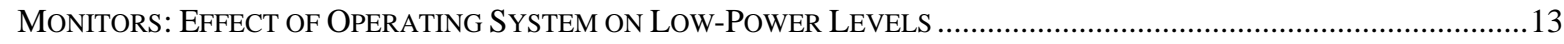

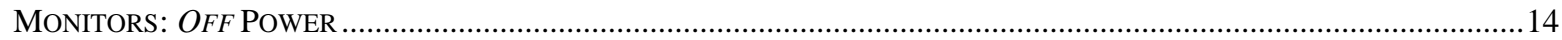

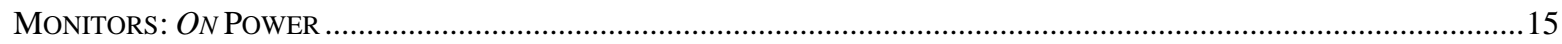

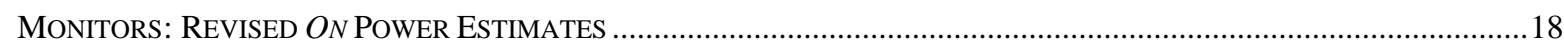

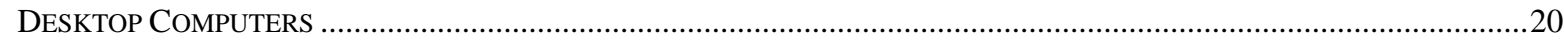

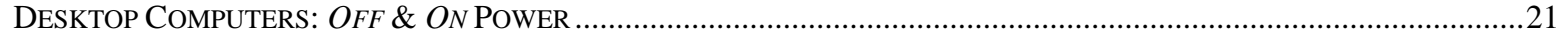

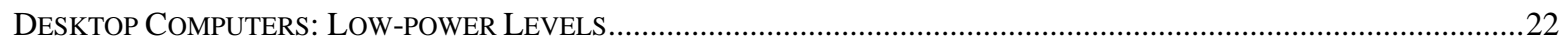

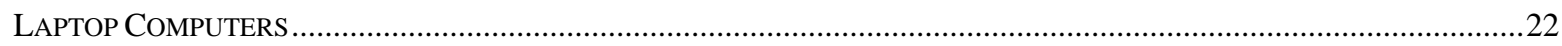

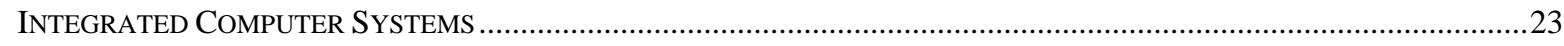

CONCLUSIONS AND FUTURE WORK.......................................................................................................24

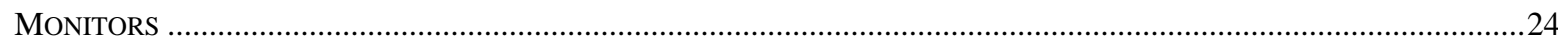

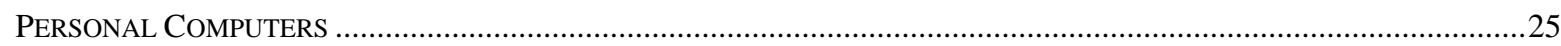

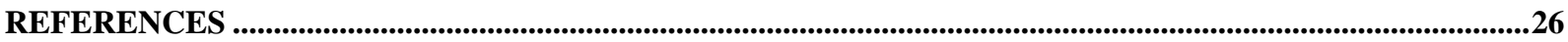

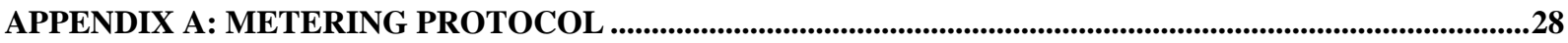

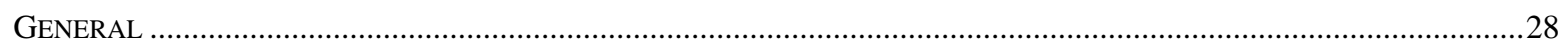

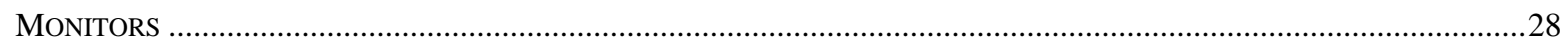

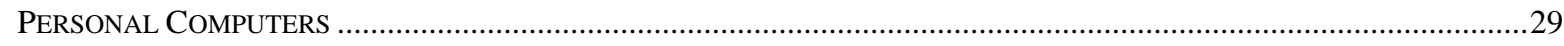

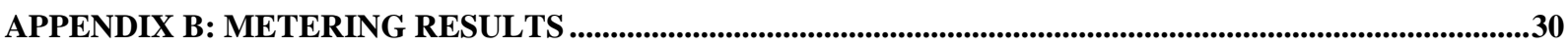

APPENDIX C: STATISTICAL ANALYSIS OF MONITOR POWER LEVELS, BY TYPE \& SIZE ................32 


\section{List of Tables}

Table 1. Key Product Criteria for ENERGY STAR Labeled Computers........................................................4

Table 2. Definition of Power Management Terms As Used in this Report ............................................6

Table 3. Distribution of Monitors in Sample, by Type and Size …......................................................

Table 4. Statistical Analysis of All Monitors, All Power Levels .............................................................11

Table 5. Comparison of Off Power for Monitors that Consume Power when Off ....................................14

Table 6a. Average Monitor On Power per Unit Display Area (W/in ${ }^{2}$, approximate)................................17

Table 6b. Average Monitor On Power per Unit Display Area (W/ $\mathrm{cm}^{2}$, approximate) ................................ 17

Table 7. Median Monitor Power Consumption by Monitor Type and Size..............................................17

Table 8. Variation in Monitor On Power (W), for Selected Monitors ....................................................19

Table 9. Statistical Analysis of Desktop Computer Power Levels ..........................................................20

Table 10. Measured Desktop Computer On Power by CPU Brand, Model, and Speed ..............................21

Table 11. Statistical Analysis of Laptop Computer Power Levels .........................................................23

Table B-1. Monitor Metering Results (Sorted by Monitor Type \& Size) .......................................................30

Table B-2. Desktop Computer Metering Results (Sorted by On Power) .................................................31

Table B-3. Laptop Computer Metering Results (Sorted by On Power) ....................................................31

Table B-4. Integrated Computer System Metering Results (Sorted by On Power) ......................................31

Table C1. Monitor Off Power (W), by Monitor Type \& Size .................................................................32

Table C2. Monitor On Power (with PC Off), by Monitor Type \& Size …................................................32

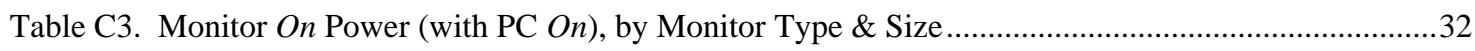

Table C4. Monitor Deep Sleep Power, by Monitor Type \& Size ..................................................................32

\section{List of Figures}

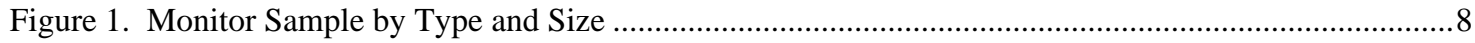

Figure 2. Statistical Analysis of All Monitors, Most Power Levels ..........................................................11

Figure 3. Monitor Recovery Time by Monitor Type and Deep Sleep Power Savings (W)...........................12

Figure 4. Average Monitor On Power Consumption (W) per Approximate Display Area ...........................16

Figure 5. Statistical Monitor On Power Consumption by Type and Size ................................................... 16

Figure 6. Statistical Analysis of Desktop Computer Power Levels .........................................................20

Figure 7. Measured Desktop Computer On Power by CPU Brand, Model, and Speed...............................21

Figure 8. Statistical Analysis of Laptop Computer Power Levels .............................................................23 


\section{Abbreviations and Acronyms}

\section{As Used in This Report}

ACPI Advanced Configuration and Power Interface

APM Advanced Power Management

CPU central processing unit

CRT cathode ray tube

ICS integrated computer system

LBNL Lawrence Berkeley National Laboratory

LCD liquid crystal display

OS operating system

PC personal computer (a generic term that includes laptop computers, desktop computers and integrated computer systems; it includes both Apple and Intel-architecture machines)

PLM power line meter

PM power management

UC University of California

\section{Acknowledgements}

We Thank the Following

Reviewers: Chris Calwell (Ecos Consulting);

Joe Eto, Jeff Harris, Karen Herter, Alan Meier (LBNL)

Individuals: Kevin Gauna, Steve Greenberg, and Erik Page (LBNL)

Institutions: UC Berkeley Building Science Lab, Chancellors Office, and The Scholars Workstation; City of Berkeley Dept of Information Technology

San Jose State University Spartan Book Store

Manufacturers: Gateway, Phillips, ViewSonic

Retailers: Best Buy, Circuit City, Gateway Country Stores, Office Depot 


\title{
Energy Use and Power Management in New Personal Computers and Monitors
}

\author{
Judy A. Roberson, Gregory K. Homan, Akshay Mahajan, \\ Carrie A. Webber, Bruce Nordman, Richard E. Brown, \\ Marla McWhinney, and Jonathan G. Koomey \\ Lawrence Berkeley National Laboratory
}

\begin{abstract}
Our research was conducted in support of the EPA ENERGY STAR Office Equipment program, whose goal is to reduce the amount of electricity consumed by office equipment in the U.S. The most energy-efficient models in each office equipment category are eligible for the ENERGY STAR label, which consumers can use to identify and select efficient products. As the efficiency of each category improves over time, the ENERGY STAR criteria need to be revised accordingly.

The purpose of this study was to provide reliable data on the energy consumption of the newest personal computers and monitors that the EPA can use to evaluate revisions to current ENERGY STAR criteria as well as to improve the accuracy of ENERGY STAR program savings estimates. We report the results of measuring the power consumption and power management capabilities of a sample of new monitors and computers. These results will be used to improve estimates of program energy savings and carbon emission reductions, and to inform revisions of the ENERGY STAR criteria for these products.

Our sample consists of 35 monitors and 26 computers manufactured between July 2000 and October 2001; it includes cathode ray tube (CRT) and liquid crystal display (LCD) monitors, Macintosh and Intelarchitecture computers, desktop and laptop computers, and integrated computer systems, in which power consumption of the computer and monitor cannot be measured separately. For each machine we measured power consumption when off, on, and in each low-power level. We identify trends in and opportunities to reduce power consumption in new personal computers and monitors.

Our results include a trend among monitor manufacturers to provide a single very low low-power level, well below the current ENERGY STAR criteria for sleep power consumption. These very low sleep power results mean that energy consumed when monitors are off or in active use has become more important in terms of contribution to the overall unit energy consumption (UEC). Current ENERGY STAR monitor and computer criteria do not specify off or on power, but our results suggest opportunities for saving energy in these modes. Also, significant differences between CRT and LCD technology, and between field-measured and manufacturer-reported power levels reveal the need for standard methods and metrics for measuring and comparing monitor power consumption.
\end{abstract}




\section{Introduction}

Energy conservation through equipment efficiency is an essential component of international and U.S. efforts to slow global warming and prevent the potentially catastrophic effects of climate change, caused primarily by increased atmospheric carbon dioxide levels that result from burning fossil fuels. In 1992 the U.S. passed the Energy Policy Act and signed the international Earth Summit treaty, both of which committed the federal government to actively reducing greenhouse gas emissions from all major sectors of the economy, including commercial office equipment (EPAct 1992, US EPA 2002b).

The proliferation of personal computers (PCs) and monitors in the 1980s and 1990s prompted the Environmental Protection Agency (EPA) to launch the voluntary ENERGY STAR energy conservation program, which encourages manufacturers of computer hardware and operating system (OS) software to incorporate available power management technology into their products, which consumers can identify by the ENERGY STAR® label. ${ }^{1}$ Power management (PM), initially developed to extend the time that portable computers could be used without recharging the battery, is now commonly used to automatically reduce the energy used by office equipment that is on but idle, or not in active use (Webber et al. 2001).

Personal computers and monitors currently account for approximately $40 \%$ of all energy consumed by office and telecommunications equipment in U.S. commercial buildings (Roth et al. 2002). Energy saved by power management in office equipment is currently estimated at $23 \mathrm{TWh} / \mathrm{year}$, with another 17 TWh/year of savings possible if PM were present and functional in all office equipment (Kawamoto et al. 2001). Effective use and continued development of power management technology will continue to be an important tool in the overall strategy for reducing energy used by office equipment (Nordman et al. 2000).

This report presents the methods and results of measuring the power management characteristics of a sample of monitors and computers manufactured between July 2000 and October 2001. The sample includes both liquid crystal display (LCD) and cathode ray tube (CRT) monitors, and both Apple and IBM compatible personal computers. For the purposes of this report, the term "personal computer" includes both Apple and Intel-architecture desktop computers, laptop computers, and integrated computer systems (ICSs). An ICS is a computer and monitor - either separate or integrated - that share a single power supply, which makes it very difficult (without sophisticated equipment) to separately measure power consumption of the two components.

For each machine, we measured power consumption when off, on and in each low-power level, under typical (as-found) operating conditions, at a single point in time. We then compared measured power levels to current ENERGY STAR power management criteria and manufacturer-reported power levels. Our results will be used to improve Office Equipment program savings estimates, inform revisions of the ENERGY STAR criteria for these products, and identify opportunities for improving ENERGY STAR program development and implementation.

\section{Background}

The following information provides additional context in which to interpret the results of our metering.

\footnotetext{
1 The ENERGY STAR $®$ program has since expanded to include other office equipment products, appliances, consumer electronics, building materials and components, HVAC and refrigeration equipment, commercial buildings, and new homes. It is now jointly administered by the U.S. EPA and DOE (http://energystar.gov).
} 


\section{Estimates of Savings from Office Equipment Power Management}

For each category of office equipment, reliably estimating the energy saved by power management (PM) depends on assessing the following factors as accurately as possible:

- Total equipment stock (calculated from estimated annual shipments and equipment lifetime),

- Average power consumption in each operating mode (off, on, and low power), ${ }^{2}$

- Typical usage patterns (percent of time the equipment spends in each operating mode), and

- PM success rates (the percent of equipment in which PM is present, enabled, and functional).

The last three factors can be combined to yield a typical unit energy consumption (UEC), which when multiplied by equipment stock provides an estimate of total annual energy consumption. Comparing this with estimated energy consumption in the absence of PM provides annual savings from PM (Kawamoto et al. 2001, Nordman et al. 2000).

Office equipment manufacturers that participate in the ENERGY STAR program regularly provide EPA with a list of compliant models (i.e., those that meet the criteria and are therefore eligible for the ENERGY STAR label) and their relevant characteristics, including power used in each power mode. This information is compiled in a database used by the government to evaluate program achievements and complemented by data collected by LBNL, including field surveys of office equipment usage patterns and enabling rates (Webber et al. 2001), and field measurements of power consumption (Nordman et al. 1996).

The purpose of this study was to provide reliable data on the energy consumption of new PCs and monitors that EPA can use to evaluate revisions to current ENERGY STAR criteria as well as to improve the accuracy of ENERGY STAR program savings estimates.

\section{Energy Star Criteria}

For a given type of office equipment, a particular model is eligible to bear the ENERGY STAR label if its manufacturer participates in the ENERGY STAR program, and it meets ENERGY STAR criteria for energy consumption while in low-power mode (any power level between off and on). For each category of office equipment (e.g., computers, monitors), the ENERGY STAR criteria are chosen so that the (approximately) $25 \%$ most energy-efficient models are eligible for the ENERGY STAR label. ${ }^{3}$ To the extent that consumers and purchasers use the ENERGY STAR label to identify and buy energy-efficient products, this provides an incentive for equipment manufacturers to improve the efficiency of their products, and as the energyefficiency of each equipment category improves over time, the relevant ENERGY STAR criteria need to be revised accordingly. Our tables and charts of our measured power levels includes $25^{\text {th }}$ percentile values, which serve to identify, at least among our sample of new machines, an approximate target for a proposed revision of ENERGY STAR criteria for those products.

In this study we are not concerned with ascertaining whether products that bear the ENERGY STAR label are "compliant" with ENERGY STAR criteria. We are, however, interested in measuring the actual low power levels achieved by both ENERGY STAR and non-ENERGY STAR products. In other words, we want to

\footnotetext{
2 The terms off, on, and low-power are defined in a later section of this report.
}

${ }^{3}$ Original ENERGY STAR product criteria did not include energy consumption while in off or on mode, but because of the growing proportion of off and on modes in product UEC, some criteria are being revised to include off and on power. In these cases, the revised off, on, and sleep criteria are selected so (approximately) $25 \%$ of products on the market meet the combined (as opposed to individual) criteria. 
evaluate the impacts of the ENERGY STAR program on the industry as a whole, not to evaluate the degree of individual partner compliance with the program.

\section{Monitors}

The ENERGY STAR monitor Memorandum of Understanding (MOU) (US EPA 1999b) defines a monitor as:

"a cathode-ray tube (CRT), flat panel display (e.g., a liquid crystal display) or other display device and its associated electronics. A monitor may be sold separately or integrated into the computer chassis. This definition is intended primarily to cover standard monitors designed for use with personal computers. The following may also be considered a monitor: mainframe terminals, and physically separate display units".

Current ENERGY STAR monitor criteria (Version 3.0, effective July 1, 1999) specify two low-power modes: $\leq 15 \mathrm{~W}$ in sleep, and $\leq 8 \mathrm{~W}$ in deep sleep, regardless of monitor size or type (US EPA 2002a). The ENERGY STAR terms sleep and deep sleep do not necessarily correspond to the terms used by monitor or OS software manufacturers to describe low-power levels. In effect, deep sleep is a monitor's lowest low-power level (above off), while sleep refers to a second, higher power level, if any.

\section{Computers}

The ENERGY STAR computer MOU (US EPA 1999a) defines a computer as:

"a desktop, tower or mini-tower, or portable unit...To qualify the unit must be capable of being powered from a wall outlet, but this does not preclude units that are capable of being powered from a wall outlet and also from a battery..."

The same computer MOU defines integrated computer systems (ICS) as:

"(s)ystems in which the computer and visual display monitor are combined into a single unit. Such systems must meet all of the following criteria: it is not possible to measure the power consumption of the two components separately; and the system is connected to the wall outlet through a single power cable".

Current ENERGY STAR computer criteria (Version 3.0, Tier 2, effective July 1, 2000) specify a single lowpower mode - sleep - according to the maximum continuous output rating of the computer's power supply, as seen in Table 1. Guideline A applies to most computers (including all desktop computers in our sample), which are not on a network or whose network connectivity does not interfere with their ability to sleep. Guideline B applies to computers whose network connectivity in sleep requires involvement of the processor and/or memory (US EPA 1999a)(US EPA 2002a).

Table 1. Key Product Criteria for Energy Star Labeled Computers

\begin{tabular}{|c|l|}
\hline & Power Consumption in Sleep Mode \\
\hline Guideline A: & \\
Power Supply Output Rating (W) & \\
$\leq 200$ & $\leq 15 \mathrm{~W}$ \\
$201-300$ & $\leq 20 \mathrm{~W}$ \\
$301-350$ & $\leq 25 \mathrm{~W}$ \\
$351-400$ & $\leq 30 \mathrm{~W}$ \\
$>400$ & $\leq 10 \%$ of power supply's maximum continuous output rating (W) \\
OR & \\
\hline Guideline B: & $\leq 15 \%$ of power supply's maximum continuous output rating (W) \\
\hline
\end{tabular}

${ }^{4}$ Whether Guideline A or B applies to a given computer model is determined by the manufacturer of that computer. 
Current criteria for ENERGY STAR integrated computer systems (ICSs) is that they use $\leq 35 \mathrm{~W}$ in sleep (US EPA 2002a).

Currently, the EPA considers laptop (a.k.a. mobile, notebook, or portable) computers to be covered by its computer criteria. However, the technology and power characteristics of laptop computer are distinct enough from desktop computers that in this report we will treat desktop computers, laptop computers, and integrated computer systems are separate equipment categories, and refer to them collectively as PCs (personal computers).

\section{Power Management: Technology}

Power management introduces one or more power levels that are intermediate between on and off. In each successive low-power level, more internal hardware devices are slowed down or turned off, and more time is required for the equipment to recover, or wake up. Terms used to describe low-power levels vary extensively between hardware and software manufacturers and versions. Efforts are underway to standardize PM terminology (Nordman et al. 2002).

In general, power management in monitors is simpler, more reliable, and more important (in terms of potential energy savings) than in PCs. Though most new monitors are capable of PM, they require that a signal be sent from the PC through the video card before PM can be initiated (Nordman et al. 1997).

Power management in personal computers (PCs) involves effective communication between the BIOS (Basic Input-Output System), hardware (the processor and peripheral devices), and software, primarily the operating system. According to Nordman et al (1997), four conditions must be satisfied in order for PM to be accomplished:

"The first is to monitor activity levels of the processor, input devices (such as the keyboard and mouse), and communication peripherals (network or modem). The second component is to utilize timers to decide when to initiate the shift to a lower power mode. Third, changes in power management status need to be communicated to the correct device and actually occur. Finally, power management needs to recognize when activity resumes and return to a higher power (or full-power) mode."

Early versions of PM, including APM (Advanced Power Management, which was introduced in 1993), were controlled primarily by the BIOS, with minimal involvement of the operating system. Enabling PM was often difficult because (1) PM settings vary widely between BIOS manufacturer and version, (2) the BIOS is usually only accessible during boot-up, and (3) numerous conditions had to be met in order for PM to function, while a failure of any single condition would prevent PM from occurring.

When Intel introduced ACPI (Advanced Configuration and Power Interface) in 1998, primary control of PM features shifted from the BIOS to the operating system (OS). This change meant that PM settings could be changed during normal computer operation, not just during boot-up. Also, PM interfaces in the OS were simpler than those in the BIOS, although there was still significant variation between OSs. ACPI effectively standardized PM technology among Intel-architecture PCs; Apple PCs employ PM technology that is distinct from but similar to ACPI (Nordman et al. 1996, Nordman et al. 1997).

\section{Power Management: Terminology}

Power management is complicated by the confusion of terminology used to describe low-power levels. Manufacturers of hardware, BIOS, and operating systems all provide some PM functionality and use their own terminology in the user interface. Because of the complex and evolving nature of system interaction (e.g., BIOS and OS, computer and monitor), and endless possible equipment combinations, the PM 
functionality that actually results in PC-monitor systems is both unpredictable and inconsistent, and there is no consensus on the definitions or use of power management terms.

Consider for example, the seemingly simple terms on and off. Power used by a PC when on depends on the level of processor activity, so it is often useful to distinguish "on-active" (when the computer is actually computing) from "on-idle" (when computing functions are fully available but not in use, so the processor can be stopped). Similarly, off in PCs can be either a "hard off," in which the computer consumes no power because the power button is on the high voltage side of the power supply, or "soft off," in which the computer consumes some power because the power button is on the low voltage side of the power supply. Associated with "soft off," "hibernate" is not a separate power mode but rather a process in which the system state is saved to disk before turning off, allowing the computer to be turned on without restarting the operating system or applications.

The terms just defined here for PCs can serve to describe their on and off power levels, but still other terms are needed to describe PC low-power levels (between on and off). Further complexity is added because the number of on, off, and low-power levels varies with each type of office equipment.

Given the lack of any standardized definitions or use of PM terminology, it is all the more important that PM terms be carefully defined and consistently used, at least within each research project or report. In this report, terminology used in a BIOS or OS interface is placed in quotes (e.g., "standby") but we do not attempt to directly correlate the low-power levels that we measured to any of these PM terms. Rather, we are primarily concerned with measuring the power consumed in all available low-power levels, and comparing the power used at each level to the power used when the equipment is off and on. In addition, in order to inform EPA's revision of relevant ENERGY STAR criteria, we must also establish some correspondence between measured low-power levels and the criteria for monitors and PCs.

For purposes of this report, we use the italicized terms off, on, sleep, and deep sleep to refer to measured power levels. Sleep and deep sleep are based on terms used in the ENERGY STAR criteria. Table 2 provides our definitions.

Table 2. Definition of Power Management Terms As Used in this Report

\begin{tabular}{|c|c|c|}
\hline & Personal Computers & Monitors \\
\hline Off & \multicolumn{2}{|c|}{ The unit is plugged in (powered), the power button is in off position and the power indicator is dark. } \\
\hline $\begin{array}{l}\text { Deep } \\
\text { Sleep }\end{array}$ & Not applicable & The lowest low-power level between on and off. \\
\hline Sleep & The lowest power level between on and off. & The lowest low-power level between on and deep \\
\hline On & $\begin{array}{l}\text { The power button is in the on position, the power } \\
\text { indicator is green. * }\end{array}$ & $\begin{array}{l}\text { The power button is in the on position, the power } \\
\text { indicator is green, and the screen display is an "empty } \\
\text { desktop" (as-found on bootup) }\end{array}$ \\
\hline
\end{tabular}

*Note: Computer on power can vary considerably depending on the degree of processor activity. In this report, we measured on power when the processor was idle, so our measurements represent minimal computer on power.

\footnotetext{
5 Because it is confusing to have two definitions for sleep, we considered defining sleep as the lowest power level in monitors as well as computers. However, that would require eliminating EPA's term deep sleep for monitors and introducing another term (e.g., light sleep) for the higher low-power level, introducing an additional element of confusion that we thought would effectively offset any benefit.
} 


\section{Description of Sample}

To characterize the energy category, we selected and metered a sample that reflects (but is not necessarily representative of) the range of brands, cost, size, and type of models in the US market. To obtain our sample, we visited local offices and office equipment retailers; from models available to us in those locations, we selectively metered the number and type of units that we estimated to reflect the market, based on available data about market share by equipment manufacturer. We present a statistical analysis of the data, but recognize that because of the small sample size, particularly for the computer categories, our results may not be statistically significant.

Our sample includes only one unit of each model. We did not attempt to evaluate the consistency of power consumption between units of the same model. We did meter duplicate units of one model; the resulting values for each power mode were within $1 \mathrm{~W}$; only one set of results is included in our sample.

We report data for 35 monitors and 26 PCs, of which 14 are desktop computers, nine are laptops, and three are integrated computer systems. All units were manufactured between July 2000 and October 2001. For models that did not exhibit a manufacturing date on their nameplate, we estimated the date by subtracting a month from the date purchased (if the unit was metered in an office) or acquired (if metered in a retail showroom). About halfway the through the metering we began recording unit cost (if it was in an office) or retail price (if it was in a showroom). We used this information to ensure the diversity of that sample.

\section{Monitors}

Monitor size is measured diagonally and rounded to the nearest inch. For CRT monitors, actual size is usually about an inch less than nominal (manufacturer list) size because the visible area of the tube is reduced when surrounded by (set into) the housing. Unless otherwise noted, this report describes CRT monitors by their nominal size. For LCD monitors there is no distinction between actual and nominal size. Our sample includes four CRT sizes: 15", 17", 19", 21;" and three LCD sizes: 15", 17" and 18."

The sample of 35 monitors is characterized as follows:

Type: Nineteen (54\%) are cathode ray tube (CRT); sixteen (46\%) are liquid crystal display (LCD). ${ }^{6}$

Brand: Acer, Compaq, Dell, Gateway, HP, KDS, Micron, NEC, Philips, Samsung, Sony, ViewSonic.

Price: Of eight CRTs for which we have costs, the range was $\$ 270$ to $\$ 1,000$; of the six LCDs for which we have costs, the range was $\$ 380$ to $\$ 920$.

Year: Ten of the monitors were manufactured in 2000; 25 were manufactured in 2001. Five did not exhibit a manufacturing date; we estimated the date as described above.

Location: Fifteen monitors were metered in retail showrooms, and twenty were metered in offices either at LBNL, the UC Berkeley campus, or the City of Berkeley.

Operating System: Three monitors were used with Macintosh desktop computers; the other 32 were connected to desktop computers with a Windows OS. Of the latter, eight used Windows 98, one used Windows NT, eleven used Windows 2000, five used Windows ME, and seven Windows XP.

\footnotetext{
6 A potential source of confusion is that some new CRT monitors have flat (as opposed to slightly convex) screens and are variously advertised as "flat-screen" or "flat-display" monitors. These flat CRT screens should not be (but are easily) confused with "flat-panel" technology, which includes both LCD and plasma monitors.
} 
Size: See Table 3 and Figure 1 below.

Table 3. Distribution of Monitors in Sample, by Type and Size

\begin{tabular}{|c|ccc|ccc|}
\cline { 2 - 7 } \multicolumn{1}{c|}{} & \multicolumn{2}{c|}{ CRT monitors (nominal size) } & \multicolumn{3}{c|}{ LCD monitors } \\
\hline Size & Count (n) & \% of CRTs & \% of Sample & Count (n) & \% of LCDs & \% of Sample \\
\hline $\mathbf{1 5 "}$ & 4 & $21 \%$ & $11 \%$ & 9 & $56 \%$ & $26 \%$ \\
$\mathbf{1 7}^{\prime \prime}$ & 5 & $26 \%$ & $14 \%$ & 4 & $25 \%$ & $11 \%$ \\
$\mathbf{1 8}^{\prime \prime}$ & 0 & - & - & 3 & $19 \%$ & $9 \%$ \\
$\mathbf{1 9 "}$ & 6 & $32 \%$ & $17 \%$ & 0 & - & - \\
$\mathbf{2 1 "}$ & 4 & $21 \%$ & $11 \%$ & 0 & - & - \\
\hline all & 19 & $100 \%$ & $54 \%$ & 16 & $100 \%$ & $46 \%$ \\
\hline
\end{tabular}

About halfway through the metering period we began recording whether each piece of equipment exhibited an ENERGY STAR label, which when present, is on a nameplate, usually on the back of the unit. Of 19 monitors for which we have this information, 11 did and 8 did not have the ENERGY STAR label.

Figure 1. Monitor Sample by Type and Size
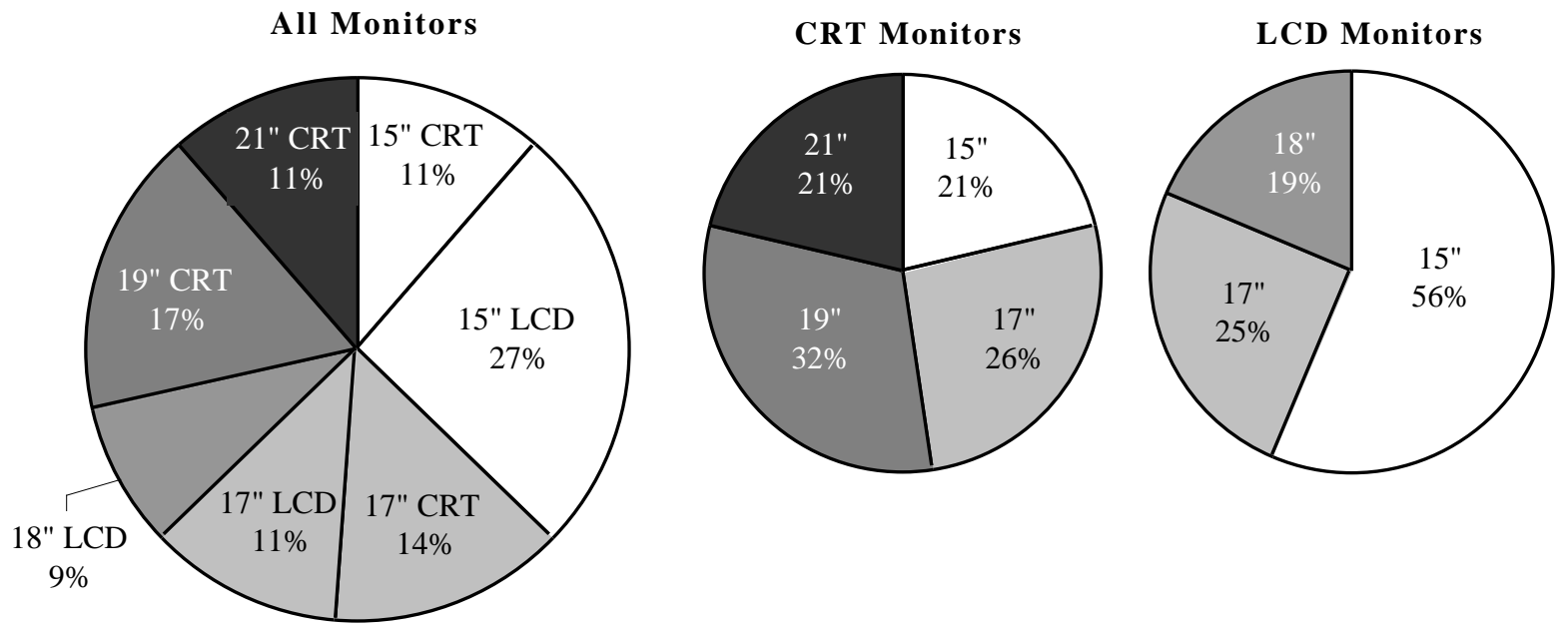

\section{Personal Computers}

The sample of 14 desktop computers consists of Compaq, Dell, Gateway, HP, Micron, and Sony brands. Processor speeds ranged from 733 to $1800 \mathrm{MHz}$. All but two (87\%) were manufactured in 2001. Seven were metered in retail showrooms; the rest were metered in offices in Berkeley CA. Seven did not exhibit a manufacturing date. Of the eight desktop computers for which we have costs, the range was $\$ 750$ $\$ 1,900$. All desktop computers in our sample used a Windows operating system: four had Windows 98 , five had Windows 2000, one had Windows ME, and four had Windows XP.

The sample of nine laptop computers consists of Apple, Dell, Fujitsu, HP, IBM, Panasonic, and Toshiba brands. Of the six (66\% of) laptops for which we have processor speed, the range was 400-1000 MHz. None of the laptops exhibited a manufacturing date; we estimated that three were manufactured in 2000 and six were manufactured in 2001. Three were metered in retail showrooms; six were metered in LBNL offices. We have costs for all nine laptops; the range was $\$ 1,199-\$ 3,134$. Four laptops used the Windows 98 OS, four used Windows 2000, and one used the Mac OS X. 
The three ICSs (integrated computer systems) in our sample are:

- An Apple iMac, in which a computer and CRT monitor are integrated into the same housing,

- A Gateway Profile, in which a computer and LCD monitor are integrated in the same housing, and

- An Apple G4 PC power-linked to an Apple Studio Display LCD monitor, in which the computer and monitor are connected by a single cable that carries power, and video and USB signals. The monitor cannot be plugged into an outlet, and the two components cannot be metered separately.

Of the three ICSs, only one unit (the Apple G4) bore a manufacturing date; their costs ranged from $\$ 949$ (for the iMac) to $\$ 3,308$ (for the Apple G4 with Studio Display monitor).

None of the eight PCs for which we looked for an ENERGY STAR label bore the label.

\section{Methodology}

\section{Metering Equipment}

Six field power line meters (PLMs) were used in our study; three model PLM-1-LP and three model PLM1-PK. All are from Electronic Product Design, Inc. (EPDI, Springfield OR), which tested and calibrated them in July and August 2000. At the end of our study in December 2001, two of the PLMs were tested at the LBNL Lighting Laboratory against a bench model Voltech PM3000A Universal Power Analyzer. The PLMs accurately measured a no-load at $0 \mathrm{~W}$, and measured the "real" power load from a nominal "75W" incandescent lamp at $72.6 \mathrm{~W}$ and $72.7 \mathrm{~W}$, compared to the bench model's measurement of $72.4 \mathrm{~W}$; i.e., the PLMs were accurate to within $0.4 \%$.

\section{Field Measurements}

Power measurement was conducted by "spot metering," in which each machine is plugged into a power meter and "real RMS" power consumption in watts (W) is measured for each power level at a single point in time. Whenever a machine entered a new power level, we waited at least 15 seconds for the power to stabilize, observed the readout for 30 seconds, and recorded the range and mode (most frequent reading) of the power readout in watts. ${ }^{7}$ Refer to Appendix A for a detailed description of our metering protocols.

Power measurements were recorded in tenths of a watt, and the results of our calculations are reported to the nearest watt.

Our measurements of monitor on power were made just after the computer booted-up and the display showed an empty (as-found, user-defined) desktop. Monitor on power actually varies considerably depending on the image displayed, and this issue is discussed in detail later in this report. Our spot measurements are intended to capture "typical" on power, but they are not standardized to a specific display and they do not capture the full range or a full duty-cycle of monitor on power consumption.

Because external USB devices (keyboard, mouse, etc.) affect power consumption, power measurements and standard test procedures should account for devices connected to USB ports. For each machine in our sample, we recorded the type of equipment (if any) connected to its USB ports, and for most machines we also recorded the number of USB ports.

\footnotetext{
${ }^{7}$ PLM measurements and calculations are updated every second.
} 
Measurements of the time required for a monitor display to recover or wake from (PC or monitor) lowpower levels are necessarily subjective and therefore should be considered as rough estimates. Recovery times were estimated to the nearest second, and the minimum recovery time recorded was 1 second, even when a display appeared to recover instantaneously. Recovery timing started with the wake event and ended when there were no further changes in brightness of the display. Recovery times are not available for many units in our sample for a variety of reasons, including the difficulty of immediately ascertaining whether a particular wake event actually initiated a recovery from low-power.

Wake events vary with the low-power level and type of communication between computer, monitor, and OS. In order of increasing "difficulty," the wake events for both personal computers and monitors are: (1) mouse movement, (2) mouse click, (3) keyboard action (hitting any key), and (4) pressing the PC power button. ${ }^{8}$ If in addition to the monitor, the computer has also entered a low-power level, a more "difficult" wake event is usually required, and the time it takes the display to recover will increase by the time it takes the computer to respond to the wake event. Estimated monitor recovery times reported in our data do not include computer recovery times.

\section{Results and Discussion}

\section{Monitors: Low-power Levels}

The current criteria for ENERGY STAR monitors specifies power consumption in two low-power modes: $\leq$ $15 \mathrm{~W}$ in sleep, and $\leq 8 \mathrm{~W}$ in deep sleep. However, $83 \%$ of monitors in our sample exhibited only one lowpower level, $94 \%$ of which were low enough to meet ENERGY STAR criteria for monitor deep sleep. This suggests a clear trend among monitor manufacturers to provide a single very low low-power level.

Table 6 below shows that among monitors in our sample, average deep sleep power for CRTs was $7 \mathrm{~W}$, but average deep sleep power for LCDs was $2 \mathrm{~W}$, which is indistinguishable from average LCD off power.

As described earlier, two objectives of our metering were to (1) identify and measure all low-power levels (between off and on), and (2) to establish some correspondence between these and the ENERGY STAR sleep and deep sleep criteria for monitors. As defined in Table 2, we determined that if a monitor exhibited one low-power level, it corresponded to the ENERGY STAR deep sleep level, and if a monitor exhibited two lowpower levels, the higher low-power level corresponded to sleep.

Based on these definitions, 34 (97\% of) monitors in our sample exhibited a deep sleep power level, and of these, 32 (94\%) met the ENERGY STAR criterion of $\leq 8 \mathrm{~W}$ in deep sleep. Thus, 32 of 35 (91\% of) monitors in our sample met the ENERGY STAR deep sleep criterion. On the other hand, only six (17\% of) monitors in our sample exhibited a sleep mode. Of these, four $(67 \%)$ met the ENERGY STAR criterion of $\leq 15 \mathrm{~W}$; the range was $6 \mathrm{~W}-10 \mathrm{~W}$.

Of the three (9\% of) monitors that did not meet ENERGY STAR criteria for sleep or deep sleep power consumption, two were used with computers run by the Windows ME operating system. Both of these exhibited two low-power modes corresponding to sleep (69) and 79W) and deep sleep (28W and 61W, respectively), all of which are well above the ENERGY STAR sleep and deep sleep criteria for monitors. The third monitor was used with a computer run by the Windows NT operating system, which does not allow power management; however, this monitor did power manage when the computer was turned off.

\footnotetext{
${ }^{8}$ In this paper the term "mouse" includes mouse equivalents such as a trackball or touch pad.
} 
To inform EPA's revision of ENERGY STAR criteria for monitor power management, we calculated minimum, maximum, average, median and quartile values for power consumption in each power level. Table 4 and Figure 2 below show the statistical analysis for all monitors in our sample; Figure 2 does not include sleep power because so few monitors in our sample exhibited sleep mode. The $25^{\text {th }}$ percentile of deep sleep power consumption is $2 \mathrm{~W}$, which is also the $50^{\text {th }}$ and $75^{\text {th }}$ percentile value. In other words, $75 \%$ of monitors in our sample used $\leq 2 \mathrm{~W}$ in deep sleep. The $25^{\text {th }}$ percentile of deep sleep power is the same (2W) for both CRT and LCD monitors, as seen in Appendix C: Statistical Analysis of Monitor Power Levels, which show results by monitor type and size.

Table 4. Statistical Analysis of All Monitors, All Power Levels

\begin{tabular}{|c|c|c|c|c|c|}
\hline Count $(\mathrm{n})$ & 35 & 34 & 6 & 28 & 35 \\
\hline All Monitors & Off $(\mathbf{W})$ & $\begin{array}{c}\text { Deep Sleep } \\
(\mathbf{W})\end{array}$ & $\begin{array}{c}\text { Sleep } \\
(\mathbf{W})\end{array}$ & $\begin{array}{c}\text { Monitor On }(\mathbf{W}), \\
\text { with PC } \text { off }\end{array}$ & $\begin{array}{c}\text { Monitor On }(\mathbf{W}), \\
\text { with PC } \text { On }\end{array}$ \\
\hline Minimum & 0 & 1 & 6 & 1 & 14 \\
$25^{\text {th }}$ percentile & 0 & 2 & 9 & 2 & 33 \\
Median/50 $/ 5$ th & 2 & 10 & 2 & 56 \\
Average/Mean & 1 & 5 & 30 & 12 & 55 \\
$75^{\text {th }}$ percentile & 2 & 2 & 54 & 3 & 74 \\
Maximum & 9 & 61 & 79 & 78 & 110 \\
\hline
\end{tabular}

Figure 2. Statistical Analysis of All Monitors, Most Power Levels

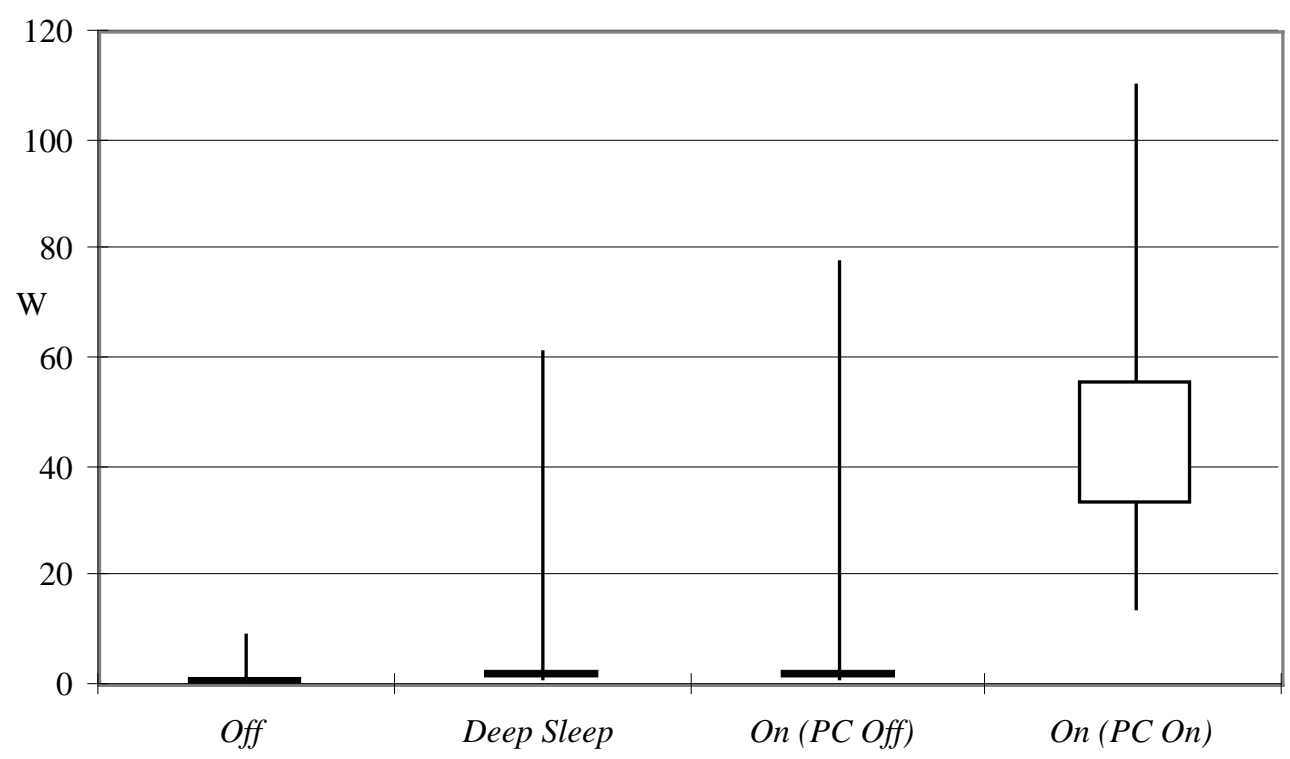

Note: The top and bottom of each box correspond to Mean and $25^{\text {th }}$ percentile values, respectively. The vertical line through each box shows the range (maximum and minimum) of measured values.

\section{Monitors: Recovery Time from Low-Power Levels}

A central issue in power management is the time it takes a machine to recover from low-power levels. Therefore, besides recording monitor low-power levels, we recorded the minimal action (wake event) required to initiate recovery from each low-power level, and the estimated time, in seconds, that it took each display to fully recover. Timing of monitor recovery began with the wake event and ended when 
there was no apparent change in the brightness of the display, and although some monitors appeared to recover instantaneously, the minimum time we recorded was 1 second. Because these observations are necessarily subjective and approximate, our resulting times should be considered to be rough estimates.

Individual results of estimated monitor recovery times are in Appendix B, Table B1. The range of recovery time from deep sleep was 1-12 seconds for CRTs, and 1-3 seconds for LCDs; the median time from deep sleep was 8 seconds for CRTs, and 2 seconds for LCDs. Figure 3 presents recovery time from deep sleep by monitor type and deep sleep power savings (or on power minus deep sleep power).

Although there is variability within the CRT and LCD samples, in general, the more power that is saved by powering down from on to deep sleep, the longer it takes a monitor to recover from deep sleep; CRTs save more power (relative to on) but take more time to recover from deep sleep than LCDs. CRTs saved 40-110 $\mathrm{W}$ in deep sleep and took 3-12 seconds to recovery; LCDs saved 10-40 W and took 1-3 seconds to recover.

Figure 3. Monitor Recovery Time by Monitor Type and Deep Sleep Power Savings (W)

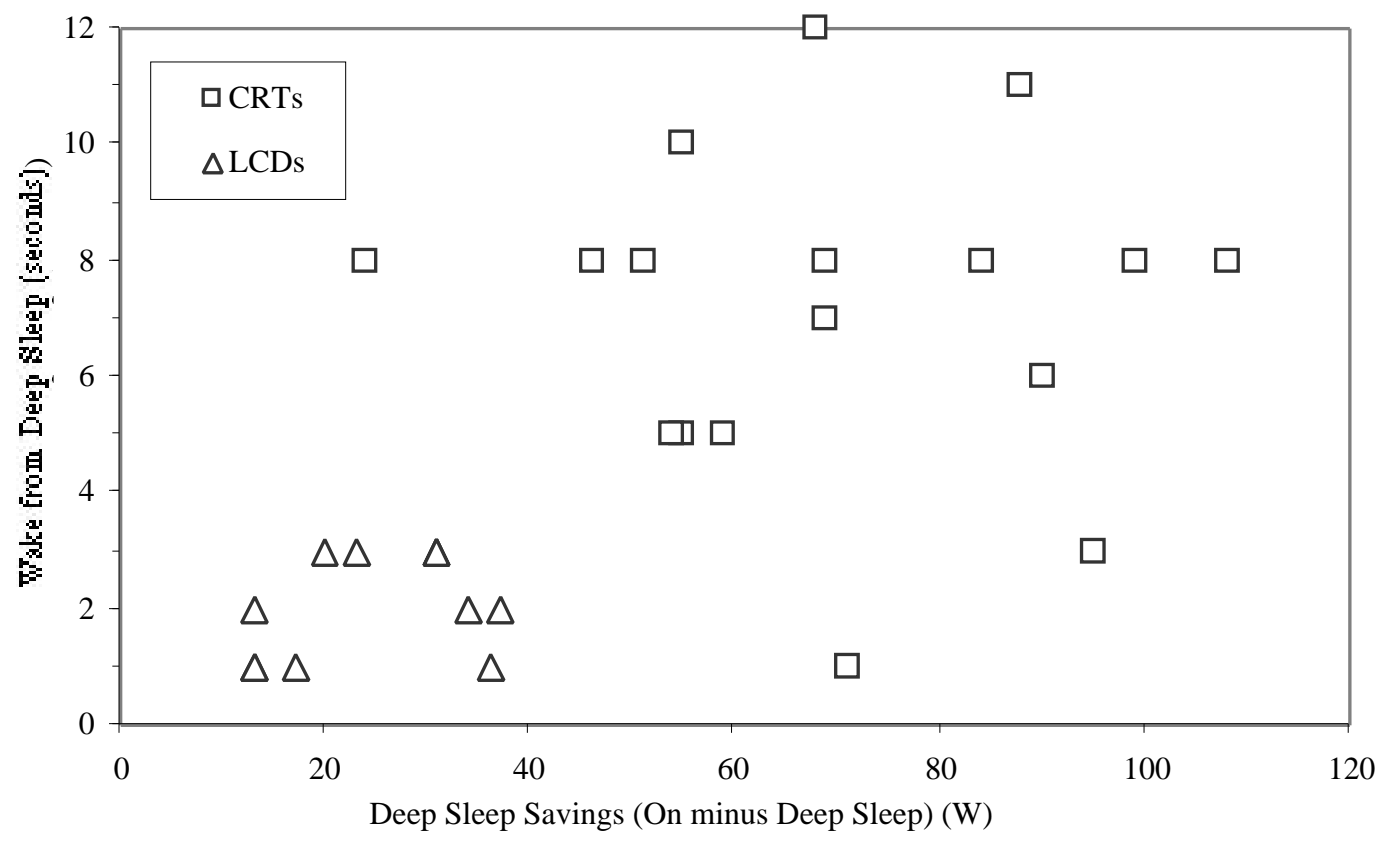

Without exception in our metering, the wake event for the automatic PM level "Turn off monitor" (Windows) and "display sleep" (Macs) was mouse movement; recovery time varied from 1-11 seconds. Although some monitors appeared to recover instantly, the minimum time recorded was "1 second."

Of three monitors in our sample run by a Mac OS, the wake event for "system sleep," both automatic and manual, was the keyboard. However, among monitors connected to desktop computers using a Windows OS, wake events from the "standby" power level varied widely among monitor brands, computer brands, and even depending on whether "standby" was initiated automatically (through the control panel) or manually. We found no correlation between "standby" wake events and monitor brand, computer brand, or Windows OS version. Of 17 desktop computers using with a Windows OS and "hibernate" mode, the computer power button was the wake event for all but one (an LCD monitor used with a computer using Windows 2000), which required only a mouse move. These observations suggest the complexity of interaction between power management features in the hardware and the OS. 


\section{Monitors: Effect of Operating System on Low-Power Levels}

Monitors depend on the computer to initiate power management (PM) through the video card. For monitors in our sample, we recorded the desktop computer operating system (OS) and the PM features and settings as-found in the appropriate OS control panel. Some operating systems (including Windows NT, as well as some Linux and Unix) do not natively ${ }^{9}$ support or allow PM. Among operating systems that do support PM, availability and nomenclature of power management (PM) features varies considerably, although PM features and terms tend to be relatively consistent among different versions of the same OS.

In the Macintosh (Mac) OS, automatic PM settings in the "energy saver" control panel are called "(system) sleep", "display sleep", and "hard disk sleep." "(System) sleep" can also be manually initiated from the "special" menu. In Macintosh PCs the BIOS is not accessible. Windows operating systems usually (but not always) have the same "turn off monitor", "turn off hard disks" and "system standby" automatic PM delay settings available in a control panel that is called "power management" in Windows 98 and "power options" beginning with Windows 2000. The "hibernate" feature, also new in Windows $2000,{ }^{10}$ must be enabled in the "power options" control panel in order for its automatic delay settings to be available in that control panel, or for it to be available for manual selection from the "start" menu.

The single (17" CRT) monitor connected to a desktop computer using Windows NT (which does not allow PM), did not sleep (power manage) when the computer was on; however, this monitor powered down to $1 \mathrm{~W}$ when the computer was off. (When the computer and monitor were both off, the monitor used $0 \mathrm{~W}$.) In this case, the Windows NT OS clearly prevents PM in a monitor that is otherwise capable of PM. Other than this discussion, this monitor's deep sleep PM level is excluded from our results and analysis, which are concerned with monitor power levels measured when the computer to which it is connected is not off.

One desktop computer that used the Windows 98 OS could also be booted up using a Linux 6.2 OS. We metered its 21" CRT monitor using both operating systems and found identical power levels (including a $2 \mathrm{~W}$ deep sleep) except on, which measured $110 \mathrm{~W}$ with Windows 98 and $118 \mathrm{~W}$ with Linux. This $8 \mathrm{~W}$ difference can be attributed to differences in color between the desktop displays of each OS. Although this monitor was metered twice (once with each OS), we used one set of results (those corresponding to the Windows 98 OS) in our subsequent analysis.

Only two (6\% of) monitors - a 19" CRT and a 21" CRT - failed to achieve ENERGY STAR power levels; both were connected to computers using Windows ME. In response to PM settings in the control panel, both monitors exhibited two successive power levels between on and off, but neither level was $\leq 15 \mathrm{~W}$. Sleep and deep sleep were $69 \mathrm{~W}$ and $61 \mathrm{~W}$ in the $19 "$ CRT, and 79W and $28 \mathrm{~W}$ in the 21 " CRT monitor.

In our monitor sample, we found one Windows 2000 and two Windows 98 desktop computers for which "standby" settings were not available in the control panel. Although their monitors could sleep, these computers were unable to automatically or manually enter "standby" mode. In one 17" LCD monitor connected to a Windows 98 desktop computer, we manipulated BIOS PM settings in an unsuccessful attempt to enable "standby" settings in the OS control panel. In three other monitors connected to desktop computer using various Windows OSs, "standby" was available wither manually or automatically, but not both. These observations reflect the inconsistency and unpredictability of PM.

\footnotetext{
${ }^{9}$ For Windows NT, add-on software is available that enables monitor power management.

${ }^{10}$ Before 2000, proprietary software was available to enable some laptop computers to "hibernate."
} 


\section{Monitors: Off Power}

In our sample, two-thirds (68\%) of CRTs used 0W when off, compared to only $12 \%$ of LCD monitors. On average, CRT monitors in our sample used $1 \mathrm{~W}$ when off, while LCD monitors used $2 \mathrm{~W}$ when off. These results agree with those of Groot and Siderius (2000), who found that while some CRT and LCD monitors used $0 \mathrm{~W}$ when off, CRTs use $1.2 \mathrm{~W}$ on average and LCDs use $2.5 \mathrm{~W}$ on average when off. However, for all monitors in our sample, including CRTs and LCDs, the $25^{\text {th }}$ percentile of off power was 0W. ${ }^{11}$ These results indicate an opportunity to reduce off power consumption, particularly in LCDs.

In discussing monitor off power, it is important to note that our results are reported to the nearest watt. On closer inspection of the measurements, which were recorded in tenths of a watt (according to the PLM readout), almost half (9) of the 19 CRTs measured $0.0 \mathrm{~W}$ when off, but none of the 16 LCDs did.

These differences between CRT and LCD off power are attributable not to their display technology, but rather to the location of the power switch relative to the power supply. A power supply receives high $(\sim 115 \mathrm{~V})$ voltage from the power main and sends low(er) voltage to the electronic components of the monitor; the monitor power switch (or button) is located either on the "high" or "low" side of the power supply. If the monitor power switch is on the high (wall) side of the power supply, the monitor is said to have a "hard off" feature because it draws no power ( $0.0 \mathrm{~W}$ with our metering protocol) when switched off. If the switch is on the low side, the power supply is said to have a "soft off" feature because is draws some power $(\geq 0.1 \mathrm{~W}$ with our protocol) from the wall outlet even when the switch is off. The power supply of CRTs is internal (within the monitor housing) but to reduce the weight and size of LCDs, their power supply is often external, with the power supply incorporated into either the plug or the power cord. Monitors with an internal power supply (e.g., CRTs) can have either a "hard off" or "soft off" switch, while monitors with an external power supply (most LCDs) use power when off because their switch is a "soft off." The amount of off power used by monitors with external power supplies depends on the efficiency or quality of their external power supply, which varies considerably.

The nine CRT monitors in our sample that measured $0.0 \mathrm{~W}$ when off clearly had a "hard off" feature. Table $\underline{5}$ compares off power of the remaining 26 monitors (10 CRTs, 16 LCDs) that had measurable $(\geq 0.1 \mathrm{~W})$ off power consumption, i.e., those monitors whose switch is on the low side of the power supply.

Table 5. Comparison of Off Power for Monitors that Consume Power when Off

\begin{tabular}{|c|c|c|c|c|}
\cline { 3 - 5 } \multicolumn{2}{c|}{} & \multicolumn{3}{c|}{ Off Power Consumption (W) } \\
\hline Monitor type & Count & Range & Average & Median \\
\hline CRT & 10 & $0.2-9.3$ & 2.1 & 1.7 \\
LCD & 16 & $0.1-3.6$ & 1.8 & 1.8 \\
\hline
\end{tabular}

When CRTs and LCDs whose power switch is on the low side of the power supply are compared, their off power consumption is similar; both average and median values for CRTs and LCDs round to $2 \mathrm{~W}$.

Off power consumption is eliminated by placing the power switch on the high side of the power supply, which requires an internal power supply. Although most LCDs currently have external power supplies, it is possible to incorporate internal power supplies, particularly in larger LCDs. Even among LCDs with external power supplies in our sample, the wide range of off power $(0.1-3.6 \mathrm{~W})$ indicates that some external

11 Note that because of rounding, "0W" means $0.0-0.4 \mathrm{~W}$, "1W" means $0.5-1.4 \mathrm{~W}$, and "2W" means $1.5-2.4 \mathrm{~W}$. 
power supplies use much less off power than others; this indicates an opportunity to reduce off power consumption in LCD with external power supplies by installing more efficient power supplies.

\section{Monitors: On Power}

Current ENERGY STAR monitor criteria do not specify power consumption in off or on mode, but to the extent that monitor size (and percent time on) continue to increase, reducing monitor on power consumption becomes more important in efforts to reduce office equipment energy use (Groot \& Siderius 2000).

The amount of power consumed by a monitor when on is primarily a function of its type (CRT, LCD), screen size, and the image displayed. LCD monitors use less energy when on than CRT monitors of similar size. The larger the screen size, the more power a monitor uses when on; this applies to both CRT and LCD monitors (Nordman et al. 1997). Image displayed is primarily a function of the user's color settings and desktop graphics, as well as the color and size of open application windows; a given monitor requires more power to display a white (or light) screen than a black (or dark) screen. Displayed image affects on power more in CRTs than LCDs, as discussed in detail below. However, brightness and contrast (which can be adjusted using controls on the front of the monitor), as well as refresh rate and resolution settings (which can be changed in the computer's OS control panels) also affect the amount of power a monitor uses when on. (These factors are further discussed below, in the section Monitors: Revised On Power Estimates.)

Comparing the energy use of monitors on the basis of screen size is problematic for several reasons. First, the actual diagonal size of the display on a nominal 19" CRT monitor is closer to 18" than 19", but the difference (whether absolute or relative) between actual and nominal CRT size is not consistent, so the only way to accurately determine the diagonal size of a CRT's actual display is to measure each CRT monitor. Second, LCD sizes do not always correspond to actual CRT sizes; e.g., our sample consists of 15", 17", and 18" LCDs, while actual sizes of CRTs in our sample are approximately 14", 16", 18", and 20" (nominal sizes 15", 17", 19", and 21", respectively); i.e., LCDs and CRTs don't always have the same diagonal sizes. Third, a given diagonal screen size has several possible aspect ratios, or height and width combinations, each with a slightly different display area. Fourth, for a given display area, there are many possible combinations of brightness, contrast, and resolution settings, all of which affect on power consumption.

Clearly, accurate comparison of monitor on power consumption requires a better metric than diagonal size; the ideal metric would normalize monitor on power consumption by unit display area. In a recent report to EPA, ECOS Consulting (Callwell \& Reeder 2002) recommends normalizing monitor on power (W) using pixel count, which is the product of horizontal and vertical resolution. "Pixels per watt" has several advantages as a basis for normalizing monitor on power consumption; besides being able to make comparisons between monitor technology and size, incongruities in resolution or aspect ratio also become irrelevant.

Unfortunately, in this study we did not record resolution settings, and so we do not have pixel counts for monitors in our sample. Nor did we record horizontal and vertical screen measurements of the actual display of each CRT, which would provide the accurate screen areas. Therefore, we instead calculate an approximate display area based on the nominal diagonal size of the monitors, assuming each monitor has an aspect ratio of 3:4 (height:width) and that CRT actual size is one inch less that its nominal size.

Table 6a presents monitor on power as a function of approximate display area in square inches, and Table $\underline{6 \mathrm{~b}}$ presents monitor on power as a function of approximate display area in square centimeters. Figures 4 and 5 display these results graphically. 
Figure 4. Average Monitor On Power Consumption (W per Approximate Display Area)

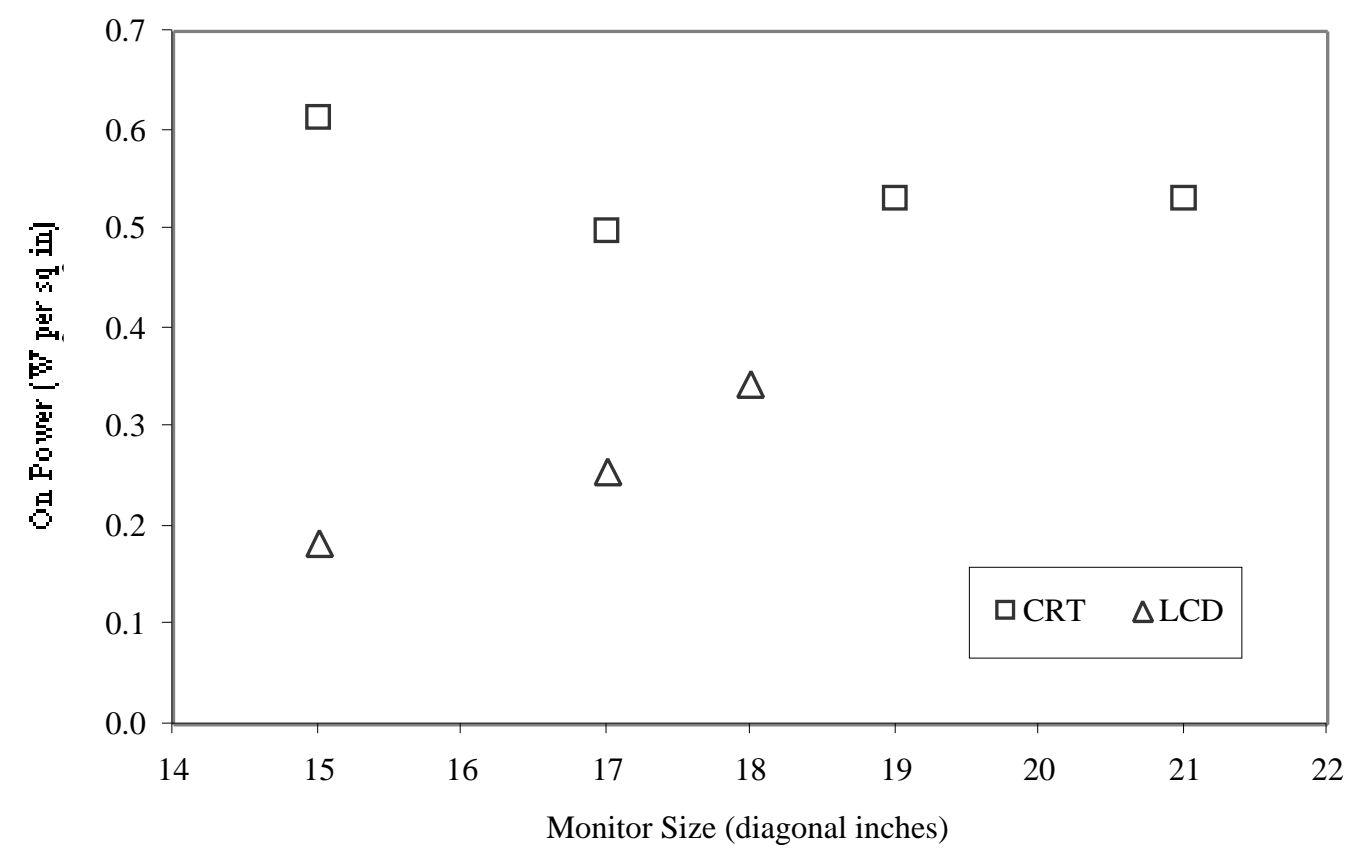

Figure 5. Statistical Monitor On Power Consumption by Type and Size

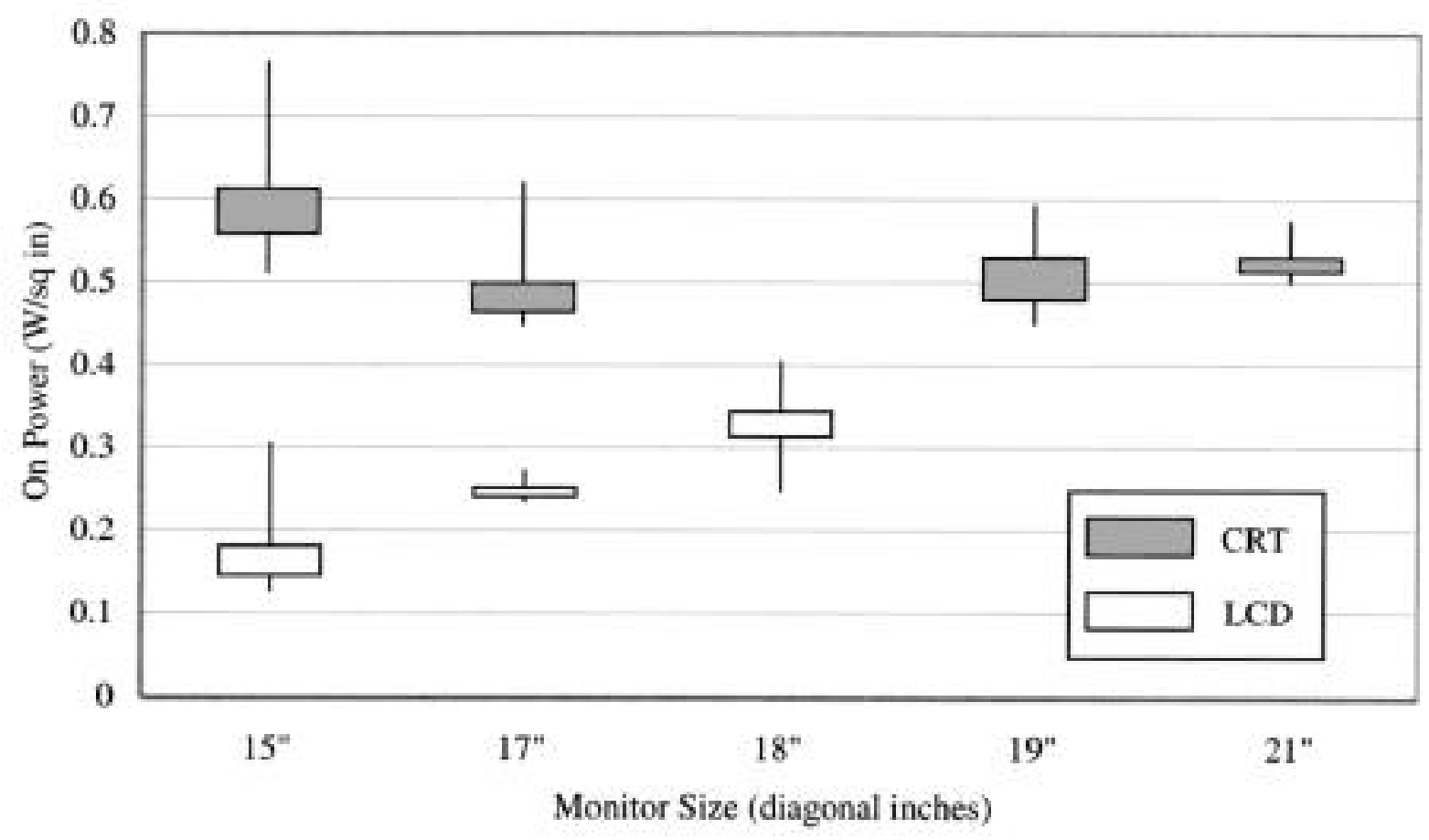

Note: The top and bottom of each box correspond to Mean and $25^{\text {th }}$ percentile values, respectively. The vertical lines through each box show the range (maximum and minimum) of measured values. 
Table 6a. Average Monitor On Power per Unit Display Area (W/in², approximate)

\begin{tabular}{|c|c|c|c|c|c|c|}
\hline Nominal Diagonal Size (in) & 15" $^{\prime \prime}$ & 17" $^{\prime \prime}$ & $\mathbf{1 8}^{\prime \prime}$ & $\mathbf{1 9}^{\prime \prime}$ & $\mathbf{2 1}$ & All sizes \\
\hline CRT On Power $\left(\mathbf{W} / \mathbf{i n}^{2}\right)$ & 0.61 & 0.50 & - & 0.53 & 0.53 & 0.54 \\
\hline LCD On Power $\left(\mathbf{W} / \mathbf{i n}^{2}\right)$ & 0.18 & 0.25 & 0.34 & - & - & 0.23 \\
\hline LCD $\left(\mathbf{W} / \mathbf{i n}^{2}\right) \div$ CRT $\left(\mathbf{W} / \mathbf{i n}^{2}\right)(\%)$ & $30 \%$ & $51 \%$ & - & - & - & $43 \%$ \\
\hline
\end{tabular}

Table 6b. Average Monitor On Power per Unit Display Area (W/cm², approximate)

\begin{tabular}{|c|c|c|c|c|c|c|}
\hline Nominal Diagonal Size (in) & 15" & $\mathbf{1 7}^{\prime \prime}$ & $\mathbf{1 8}$ & $\mathbf{1 9}$ & $\mathbf{2 1}$ & All sizes \\
\hline CRT On Power $\left(\mathbf{W} / \mathbf{c m}^{2}\right)$ & 0.10 & 0.08 & - & 0.08 & 0.08 & 0.08 \\
\hline LCD On Power $\left(\mathbf{W} / \mathbf{c m}^{2}\right)$ & 0.03 & 0.04 & 0.05 & - & - & 0.04 \\
\hline LCD $\left(\mathbf{W} / \mathbf{c m}^{2}\right) \div$ CRT $\left(\mathbf{W} / \mathbf{c m}^{2}\right)(\boldsymbol{\%})$ & $30 \%$ & $51 \%$ & - & - & - & $43 \%$ \\
\hline
\end{tabular}

Even with the uncertainties involved in our calculation of display areas, the differences between CRT and LCD on power are robust enough to confirm that LCDs consume significantly less power when on than CRTs of similar size. On average, for monitors in our sample, 15" LCDs consume 30\% as much power when on as 15" CRTs, and 17" LCDs consume 51\% as much power when on as 17" CRTs.

The data also suggest that LCD on power per unit display area increases slightly with LCD size; in other words, that the difference between CRT and LCD on power decreases as monitors get larger. Based on approximate display areas for monitors in our sample, and on average, 18" LCDs used 36\% more on power per unit area than 17" LCDs, and 88\% more on power per unit area than 15" LCDs. A possible explanation for these results is that larger LCDs have higher resolution as well as smaller pixels (higher pixel density), which require more backlighting to achieve the same level of brightness (Callwell 2002). In any case, further investigation is needed to determine if these results are borne out with a larger sample size.

Table 6 above shows average monitor on power consumption by approximate size of the display area. Table 7 shows median off, on, and deep sleep power consumption by monitor type and nominal size. Median (instead of average) values are used to exclude the outlying deep sleep power values of the two CRT monitors that did not power manage. To measure on power, we turned both the monitor and desktop computer on and waited until bootup was complete before measuring monitor on power according to the procedure detailed in Appendix A.

Table 7. Median Monitor Power Consumption by Monitor Type and Size

\begin{tabular}{|c|cc|ccc|}
\hline Monitor Type & Size & Count $(\mathbf{n})$ & Off $(\mathbf{W})$ & Deep Sleep $(\mathbf{W})$ & On $\left(\mathbf{W} / \mathbf{i n}^{2}\right)$ \\
\hline All Monitors & All & 35 & 1 & 2 & 0.45 \\
\hline CRTs & $\mathbf{1 5 "}$ & 4 & 0 & 3 & 0.58 \\
& $\mathbf{1 7 "}$ & 5 & 0 & 2 & 0.47 \\
& $\mathbf{1 9 "}$ & 5 & 0 & 2 & 0.55 \\
& $\mathbf{2 1 "}$ & 5 & 0 & 2 & 0.52 \\
& All & 19 & 0 & 2 & 0.53 \\
\hline LCDs & $\mathbf{1 5 "}$ & 9 & 2 & 2 & 0.17 \\
& $\mathbf{1 7 "}$ & 4 & 2 & 2 & 0.25 \\
& $\mathbf{1 8 "}$ & 3 & 1 & 2 & 0.38 \\
& All & 16 & 2 & 2 & 0.23 \\
\hline
\end{tabular}

For 28 ( $80 \%$ of) monitors in our sample we also measured on power when the monitor was on but the desktop computer was still off. For 23 of these, monitor on power with the computer off was within $3 \mathrm{~W}$ of monitor off power use. The other five (18\% of) monitors used $24 \mathrm{~W}-78 \mathrm{~W}$ when the monitor was on but the computer was off; these values represent $78-100 \%$ of the power used by the monitor when both monitor and 
computer are on. The results (listed in Appendix B, Table B.1 Monitor Metering Results) suggest that some monitors left on are unable to power manage when the computer to which they are connected is off. The significance of this observation is uncertain, however, because it is possible that some of these monitors would have powered down given more time than we allowed (about a minute); some monitors take up to 15 minutes to respond to the absence of a signal from the computer.

\section{Monitors: Revised On Power Estimates}

Monitors and PCs were the first products labeled by the ENERGY STAR Office Equipment program, and energy saved by power management of monitors has been and remains important to program success. As described above, the ENERGY STAR program evaluates its success by calculating the energy saved by power management of office equipment, and reliable estimates of energy savings depend in large part on accurate assessments of the power used by each product in each power level.

Based on our metering results, we estimate that monitors sold in 2001 have an average on power of $65 \mathrm{~W}$ (using data on shipments-by-type-and-size to weight the power levels resulting from this study). Previously, ENERGY STAR monitor savings estimates were based on an on value of $85 \mathrm{~W}$, which is a simple average of on power levels reported by participating manufacturers. Use of the lower $(65 \mathrm{~W})$ on power value has considerable negative impact on ENERGY STAR program savings estimates and created a situation that required us to investigate the discrepancy between measured and manufacturer-reported on power.

First we verified that our measurement techniques were generating accurate and reproducible results. As discussed earlier, our meters were tested to be accurate within $1 \%$ of the measured power level. Moreover, repeat measurement of several machines yielded results very close to our original values. We therefore concluded that our measurements accurately represent real power levels in the conditions in which we metered. Next we looked at the nature of the data reported to EPA by the manufacturers. We identified 15 monitor models in our sample that are also on EPA's list of ENERGY STAR monitors, and for which there are manufacturer-reported data. This subset includes CRTs and LCDs of a range of sizes. Without exception, manufacturer-reported on power was higher than our measured value, indicating a consistent difference in the way manufacturers either measured or reported the power data.

To determine the source of this bias, we contacted five major monitor manufacturers, three of whom responded with information. Each manufacturer used a different method to measure monitor power, but in all cases the values reported to EPA were based on a "worst case scenario;" which in the case of on power means maximum brightness and resolution, and a white screen. Also, of the manufacturers that tested multiple units of a given model, all decided to report their highest individual measurement.

We performed more detailed measurements with a limited number of monitors in our sample to determine the range of on power and the relative impact of various factors affecting monitor on power. First, without changing the as-found monitor settings, we compared on power of four displays: an empty desktop, a maximized application window (Microsoft Excel, if available, or Microsoft Word), a black screen, and a white screen. We then varied the resolution and refresh rate settings and measured on power with an empty desktop, black screen, and white screen. Not all measurements were made for each monitor. Table 8 shows the results for selected, representative monitors, The combination of white screen and maximum resolution approximates the test procedure reported by manufacturers. 
Table 8. Variation in Monitor On Power (W), for Selected Monitors

\begin{tabular}{|c|c|c|c|c|c|c|c|c|c|c|}
\hline \multirow{3}{*}{\multicolumn{2}{|c|}{$\begin{array}{c}\text { Display } \\
\text { Resolution }\end{array}$}} & \multicolumn{8}{|c|}{ Monitor On Power (W) } & \multirow{3}{*}{$\begin{array}{l}\text { Ratio of max to } \\
\text { min } O n \mathrm{~W}(\%)\end{array}$} \\
\hline & & Desktop & Application & Black & White & \multicolumn{2}{|c|}{ Desktop } & Black & White & \\
\hline & & \multicolumn{4}{|c|}{ As-found } & Min & Max & Min & Max & \\
\hline \multirow[t]{8}{*}{ CRT } & $15 "$ & 63 & 66 & 62 & 66 & 58 & & 57 & 67 & 118 \\
\hline & $15 "$ & 56 & & 48 & 57 & & & & & 119 \\
\hline & $17 "$ & 86 & 97 & 75 & 93 & 82 & 86 & 74 & 96 & 131 \\
\hline & $17 "$ & 96 & 104 & 74 & 104 & & & & & 140 \\
\hline & $19 "$ & 90 & & 86 & 103 & & & & & 120 \\
\hline & $19 "$ & 91 & 99 & 69 & 97 & 82 & 99 & 59 & 111 & 188 \\
\hline & $21 "$ & 118 & 123 & 103 & 128 & 116 & 125 & & & 124 \\
\hline & $21 "$ & 99 & & 93 & 111 & & & & & 119 \\
\hline \multirow[t]{4}{*}{ LCD } & $15 "$ & 17 & & 16 & 16 & \multirow{3}{*}{33} & & \multirow[b]{4}{*}{37} & & 106 \\
\hline & $15 "$ & 33 & & 32 & 33 & & & & & 103 \\
\hline & $18 "$ & 59 & & 57 & 59 & & & & & 104 \\
\hline & $18 "$ & 40 & & 37 & 40 & 40 & & & & 108 \\
\hline
\end{tabular}

The data in Table 8 seem to indicate that on power is more variable in CRTs than LCDs (the ratio of maximum to minimum on power ranges from 118-188\% in CRTs, compared to 103-108\% in LCDs. Among CRTs, maximum on power appears to be associated with a white display, or a maximum-sized application window (which approximates a white display). Among the few LCD monitors in the table, the power used to display a white screen is indistinguishable from power used to display the desktop. Thus, it appears that display color is a significant determinant of on power for CRTs, but not for LCDs.

However, we did not measure the full effect of brightness and contrast settings on monitor on power. Another researcher observed that these settings (whose controls are on the front of each monitor), have a greater impact on the range of LCD on power than do resolution or screen color, because a brighter LCD requires more backlighting, the most energy-intensive component of LCDs (Callwell 2002). More thorough testing is needed to characterize and quantify the effect of all these variables (monitor brightness, contrast, refresh rate, resolution, and screen color) on the range of CRT and LCD on power.

In summary, manufacturers made a good faith effort to provide accurate data to EPA, but the absence of a standard protocol for measuring and reporting power data meant that each manufacturer had to develop their own method, and each reported their worst case results for a variety of practical reasons. (Worst-case conditions are routinely used for purposes of documenting product functionality, liability, and consumer protection.)

By comparison, LBNL's metering protocols were designed to reflect typical operating conditions, on which ENERGY STAR program savings estimates are supposed to be based. As a result of our investigation into the discrepancy between measured and reported power, LBNL's measured values have replaced manufacturer-reported values for use in estimating overall energy savings from ENERGY STAR monitors.

Although the ENERGY STAR program intended to use the manufacturer-reported data to evaluate its own success in terms of energy savings, manufacturers (understandably) assumed that information they reported would or could be used to evaluate their own "compliance" with the ENERGY STAR program. ${ }^{13}$ Clearly, there is a need to more effectively communicate the program's data collection goals to participating manufacturers.

13 ENERGY STAR is a voluntary - not regulatory - program. 


\section{Desktop Computers}

Our computer sample consists of 14 desktops, nine laptops, and three integrated computer systems. While such small sample sizes may not be statistically significant, but their analysis may nevertheless provide useful insights into power use and trends among the newest generation of personal computers.

Table 9 and Figure 6 present a statistical analysis of measured power levels and estimated low-power recovery (or wake) times for desktop computers in our sample. Appendix B, Table B.2 lists the results in detail. The term light sleep is defined below in the section Desktop Computers: Low-power Levels.

Table 9. Statistical Analysis of Desktop Computer Power Levels

\begin{tabular}{|c|c|c|c|c|c|c|}
\hline Count (n) & 14 & 14 & 13 & 7 & 7 & 14 \\
\hline $\begin{array}{c}\text { All Desktop } \\
\text { Computers }\end{array}$ & $O f f(\mathbf{W})$ & Sleep $(\mathrm{W})$ & $\begin{array}{l}\text { Wake from } \\
\text { Sleep (sec) }\end{array}$ & $\begin{array}{c}\text { Light Sleep } \\
(\mathrm{W})\end{array}$ & $\begin{array}{c}\text { Wake from } \\
\text { Light Sleep (sec) }\end{array}$ & $O n(W)$ \\
\hline Minimum & 1 & 2 & 5 & 29 & 2 & 28 \\
\hline 25th percentile & 2 & 3 & 9 & 34 & 3 & 50 \\
\hline $50^{\text {th }}$ percentile/Median & 3 & 4 & 12 & 52 & 4 & 63 \\
\hline Average/Mean & 3 & 9 & 13 & 49 & 5 & 70 \\
\hline 75th percentile & 4 & 5 & 14 & 54 & 6 & 94 \\
\hline Maximum & 4 & 48 & 24 & 90 & 11 & 117 \\
\hline
\end{tabular}

Figure 6. Statistical Analysis of Desktop Computer Power Levels

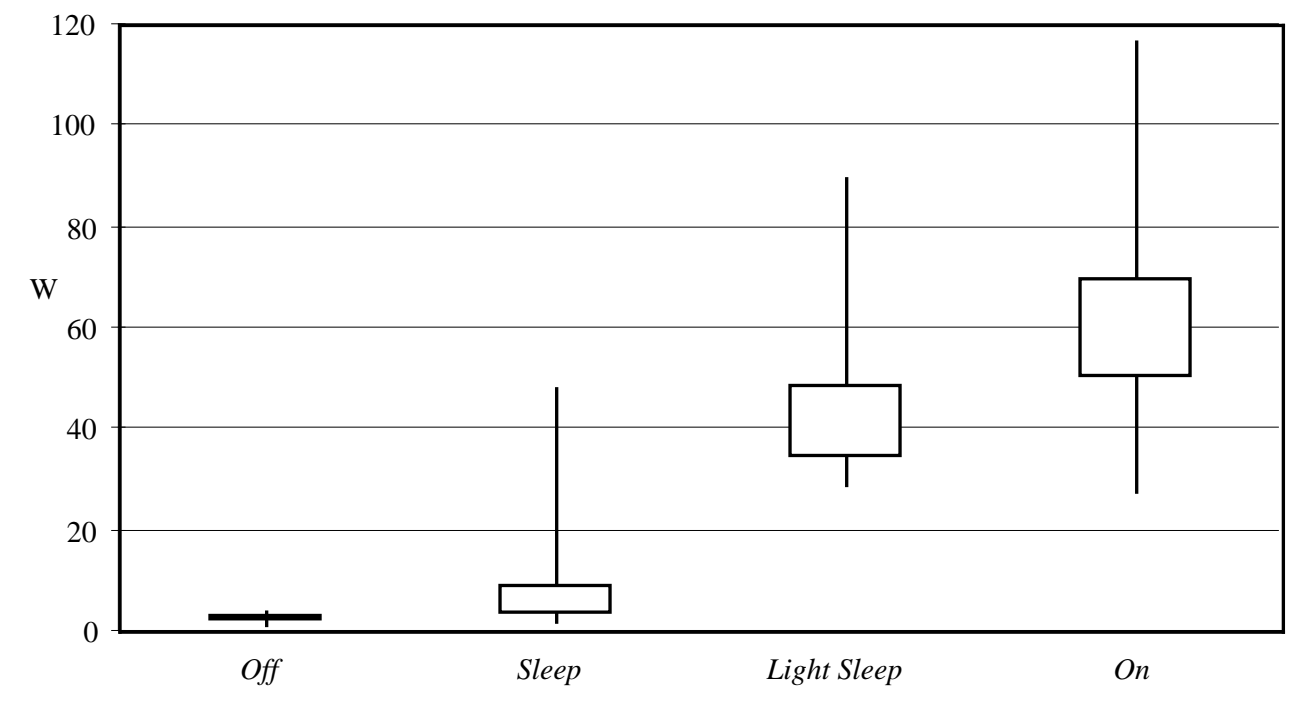

Note: The top and bottom of each box correspond to Mean and 25th percentile values, respectively. The vertical lines through each box show the range (maximum and minimum) of measured values. 


\section{Desktop Computers: Off \& On Power}

None of the desktop computers used $0 \mathrm{~W}$ when off; the range of off power was $1-4 \mathrm{~W}$, the average and median were $3 \mathrm{~W}$, and the $25^{\text {th }}$ percentile was $2 \mathrm{~W}$.

Desktop computer on power ranged from $28-117 \mathrm{~W}$; the $25^{\text {th }}$ percentile was $50 \mathrm{~W}$. Table B2, which is sorted by on $\mathrm{W}$, suggests desktop computer on power is more closely correlated with CPU make and model than with CPU speed. Although the two desktop computers with the slowest CPUs (733 MHz) also had the lowest on power $(28 \mathrm{~W}$ and $36 \mathrm{~W})$, on power of the two computers with the fastest CPUs $(1800 \mathrm{MHz})$ were $63 \mathrm{~W}$ and $94 \mathrm{~W}$; these values correspond to the $50^{\text {th }}$ and $75^{\text {th }}$ percentile, respectively, but are not among the highest on values, which are over $100 \mathrm{~W}$.

Table 10 and Figure 7 show the relationship between desktop computer on power and CPU make, model, and speed. In our sample, desktop computers with Intel Pentium 3 CPUs averaged $38 \mathrm{~W}$ when on, compared to an average 67W for desktop computers with Intel Pentium 4 CPUs, and an average of 104W for desktop computers with AMD Athlon CPUs. However, these results are not necessarily a complete indicator of processor efficiency, because CPU performance is affected by factors other than processor speed $(\mathrm{MHz})$.

Table 10. Measured Desktop Computer On Power by CPU Brand, Model, and Speed

\begin{tabular}{|c|c|c|c|c|}
\hline & \multicolumn{2}{|c|}{ CPU } & Measured On Power (W) \\
\hline Count (n) & Brand, Model & Speed Range & Range & Average \\
\hline 4 & Intel Pentium 3 & $733-1000 \mathrm{MHz}$ & $28-47$ & 38 \\
6 & Intel Pentium 4 & $1300-1800 \mathrm{MHz}$ & $59-94$ & 67 \\
4 & AMD Athlon & $1000-1400 \mathrm{MHz}$ & $93-117$ & 104 \\
\hline
\end{tabular}

Figure 7. Measured Desktop Computer On Power by CPU Brand, Model, and Speed

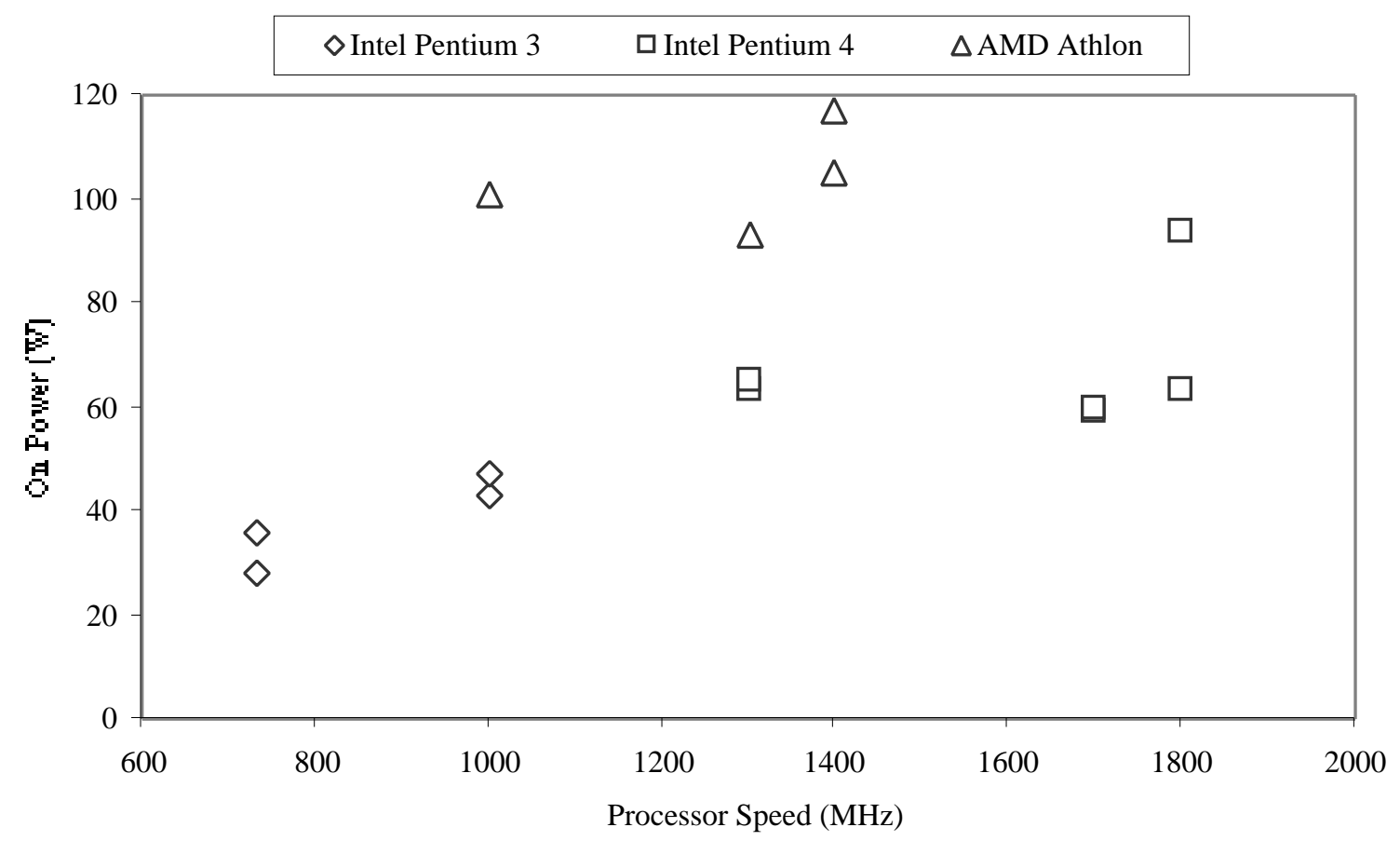




\section{Desktop Computers: Low-power Levels}

As seen in Table 1, the current criteria for ENERGY STAR computers specifies a single low-power level sleep - depending on the rated output of the power supply, in watts. In practice, is very difficult to identify the size of the rated power supply of a given computer without opening the computer housing, which was beyond the scope of our field metering protocol. We were therefore unable to determine the size of the power supply for any of the desktop computers in our sample, and discussion of our metering results in relation to ENERGY STAR computer criteria is necessarily limited to a suggestion that revisions of the computer criteria be based on a computer specification that is more readily apparent.

As with monitors, we needed to correlate measured desktop computer low-power levels with ENERGY STAR'S sleep mode, which we defined as the lowest low-power level between off and on. However, seven ( $50 \%$ of) our sample exhibited at least two low-power levels, and one exhibited three low-power levels. Therefore, for the purpose of this discussion, we define a second, higher low-power level - light sleep.

Based on this definition, sleep power consumption among all 14 desktop computers in our sample (regardless of the size of their power supplies, which we could not ascertain) ranged from 2-48W. Average sleep power was $9 \mathrm{~W}$, the median $4 \mathrm{~W}$, and the $25^{\text {th }}$ percentile was $3 \mathrm{~W}$, which is far below the lowest ENERGY STAR sleep criterion in Table 1 ( $15 \mathrm{~W}$ for computers whose power supply is $\leq 200 \mathrm{~W}$ ). This indicates that the ENERGY STAR criteria for computer sleep power needs to be revised downward.

In an attempt to correlate sleep power with a computer characteristic other than power supply, we looked for a correlation between sleep power levels and CPU brand and speed (MHz), but found none. In our sample, the range of CPU speed was $733-1800 \mathrm{MHz}$, but the two desktop computers that used the least power (2W) in sleep both had $1700 \mathrm{MHz}$ CPUs, while two of the three desktop computers that used the most power in sleep had $733 \mathrm{MHz}$ CPUs.

Based on our definition of light sleep, the seven desktop computers that exhibited a light sleep mode used from $29-90 \mathrm{~W}$ in light sleep, and the $25^{\text {th }}$ percentile for power consumption in light sleep was $34 \mathrm{~W}$.

Of 13 desktop computers for which we estimated recovery time from sleep, the range was 5-24 seconds, the average 13 seconds, and the $25^{\text {th }}$ percentile 9 seconds. Of the seven desktops for which we estimated recovery time from light sleep, the range was $2-11$ seconds, the average 5 seconds, and the $25^{\text {th }}$ percentile 3 seconds.

\section{Laptop Computers}

We measured the power consumption of nine laptop computers, all of which had a fully charged battery at the time of our measurement. Four laptops used the Windows 98 OS, four used Windows 2000, and one used Mac OS X. Table 11 and Figure 8 present the statistical analysis of laptop power levels and Appendix $\underline{B}$, Table B3 lists the laptop results in detail.

Laptops in our sample used 1-3W when off; average off power was $2 \mathrm{~W}$ and the $25^{\text {th }}$ percentile was $1 \mathrm{~W}$. On power consumption ranged from $14-25 \mathrm{~W}$; the average was $19 \mathrm{~W}$ and the $25^{\text {th }}$ percentile was $15 \mathrm{~W}$.

Eight of the nine laptops exhibited at least two low-power levels so, as with desktop computers and for the purpose of this analysis and discussion, we define a second, higher low-power level - light sleep. The range of power used in sleep was $1-8 \mathrm{~W}$, the average $3 \mathrm{~W}$, and the $25^{\text {th }}$ percentile $2 \mathrm{~W}$. The range of power used in light sleep was $2-19 \mathrm{~W}$; the average $11 \mathrm{~W}$, and the $25^{\text {th }}$ percentile $8 \mathrm{~W}$. 
Figure 8. Statistical Analysis of Laptop Computer Power Levels

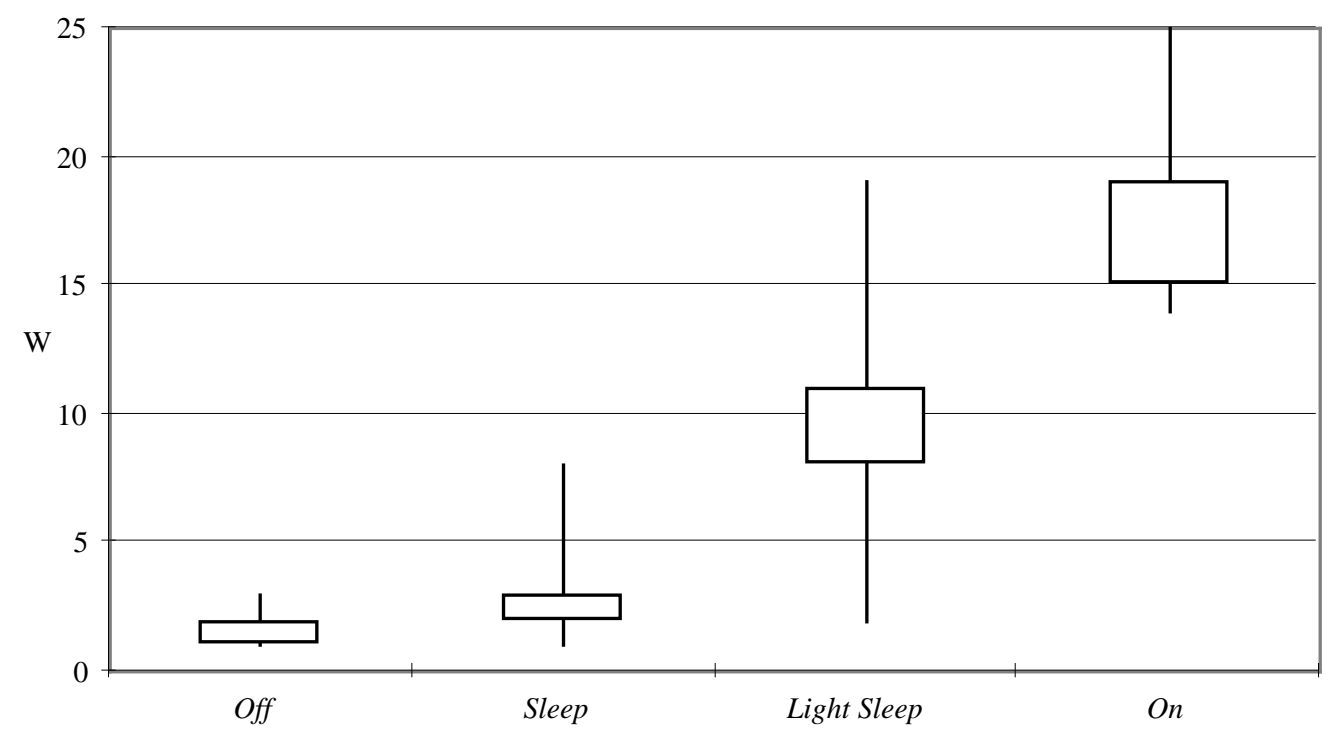

Note: The top and bottom of each box correspond to Mean and $25^{\text {th }}$ percentile values, respectively. The vertical line through each box indicate the range (maximum and minimum) of measured values.

Estimated recovery time from sleep ranged from 2-16 seconds; the average was 10 seconds and the $25^{\text {th }}$ percentile 5 seconds. Estimated recovery time from light sleep ranged from 1-4 seconds; the average was 2 seconds and the $25^{\text {th }}$ percentile 1 second.

Table 11. Statistical Analysis of Laptop Computer Power Levels

\begin{tabular}{|c|c|c|c|c|c|c|}
\hline Count $(\mathrm{n})$ & 9 & 9 & 7 & 8 & 7 & 9 \\
\hline $\begin{array}{c}\text { Laptop } \\
\text { Computers }\end{array}$ & Off $(\mathbf{W})$ & $\begin{array}{c}\text { Sleep } \\
(\mathbf{W})\end{array}$ & $\begin{array}{c}\text { Wake from } \\
\text { Sleep }(\mathbf{s e c})\end{array}$ & $\begin{array}{c}\text { Light Sleep } \\
(\mathbf{W})\end{array}$ & $\begin{array}{c}\text { Wake from Light } \\
\text { Sleep } \text { (seconds) }\end{array}$ & On $(\mathbf{W})$ \\
\hline Minimum & 1 & 1 & 2 & 2 & 1 & 14 \\
25th percentile & 1 & 2 & 5 & 8 & 1 & 15 \\
$50^{\text {th }}$ percentile/Median & 2 & 3 & 14 & 11 & 1 & 19 \\
Average/Mean & 2 & 3 & 10 & 11 & 2 & 19 \\
75th percentile & 2 & 3 & 16 & 14 & 4 & 25 \\
Maximum & 3 & 8 & 16 & 19 & 2 & 4 \\
\hline
\end{tabular}

\section{Integrated Computer Systems}

The three ICSs (integrated computer systems) in our sample are an Apple iMac, in which a computer and CRT monitor share the same housing, a Gateway Profile, in which a computer and LCD monitor share the same housing, and an Apple G4 PC power-linked to an Apple Studio Display LCD monitor, in which the computer and monitor are connected by a single cable carrying all video, USB, and power signals. The iMac used the Mac OS 9.2, the Profile used Windows ME, and the G4 used Mac OS X. Appendix B, Table B4 lists our ICS results in detail. There is no quartile analysis on this small sample.

Among the three ICSs, power used in off ranged from 4-8W; power used in on ranged from 54-131W. 
As with desktop and laptop computers, we define sleep in ICSs as the lowest low-power level between off and $o n$, and we also, for purposes of this analysis and discussion, define a second, higher low-power level light sleep. The range of sleep power in ICSs was 4-31W; the range of light sleep power was 25-102W. Current criteria for ENERGY STAR integrated computer systems is that they use $\leq 35 \mathrm{~W}$ in sleep. Based on our definition of sleep, all ICSs in our sample met the ENERGY STAR criteria. ICS recovery from sleep ranged from 7-16 seconds; recovery from light sleep ranged from 1-4 seconds.

\section{Conclusions and Future Work}

Continued improvement of the ENERGY STAR Office Equipment program depends on identifying new opportunities for saving energy, which requires ongoing field measurements to supplement data reported by manufacturers and to characterize emerging power trends as they relate to ENERGY STAR criteria. Summarized below are the primary observations resulting from our latest field measurements.

ENERGY STAR criteria have been so effective at reducing energy use by monitors and PCs that are on but idle that the energy consumed when they are off or in active use (on) has become more important in terms of contribution to the typical unit energy consumption (UEC). Current ENERGY STAR criteria do not specify off or on power, but our results suggest opportunities for saving energy in these modes.

\section{Monitors}

Trends in the monitor market are toward larger screen sizes (because they are easier to read and can display more information) and LCD monitors, which (although more expensive) require less space, use less energy for display, and recover from low-power levels more quickly than CRT monitors. Based on our sample, CRTs predominate among monitors larger than 17", while LCDs predominate within the 15" size category.

Our results reveal a clear trend among monitor manufacturers to provide a single very low low-power level. In our sample of 35 CRTs and LCDs, both the median and the $25^{\text {th }}$ percentile were $2 \mathrm{~W}$ - well below the current ENERGY STAR monitor criterion of $\leq 8 \mathrm{~W}$ in deep sleep. Among LCD monitors, average deep sleep power was indistinguishable from off. We suggest the current monitor criteria (which specifies two lowpower levels) be revised to specify a single low-power level - sleep, which is the term used to describe the single low-power level in other ENERGY STAR office equipment products.

Our difficulty in measuring recovery times from low-power levels highlights the fact that - to the extent that recovery time is considered as an element in future product criteria - the ENERGY STAR program needs to establish clear and consistent methods for measuring recovery time for any given product category.

On average, LCD monitors in our sample use $1 \mathrm{~W}$ more when off than CRT monitors. Although $1 \mathrm{~W}$ per monitor may seem insignificant, the cumulative impact on the UEC of this product category is not. Because the $25^{\text {th }}$ percentile of off power consumption in our sample was $0 \mathrm{~W}$, we suggest that the revised ENERGY STAR monitor specification include a $0 \mathrm{~W}$ off power criterion. This would provide monitor manufacturers with an incentive to install more efficient power supplies or use internal power supplies.

Regarding on power, our results confirm that LCDs consume less power per unit area than CRT monitors, but they also suggest that LCD on power consumption per unit area increases slightly with LCD size. Considering the uncertainties in our calculation of monitor display areas and the small size of our sample, the latter result is far from conclusive. We suggest that on power in LCDs merits further investigation. 
Our difficulty in comparing on power consumption among monitors in our sample highlights the need for a metric capable of normalizing on power consumption across all monitor types and sizes. We suggest the ENERGY STAR program continue to develop the proposed "pixels per watt" metric for monitor on power.

The process of resolving the discrepancy between measured and reported monitor on power revealed opportunities for improving ENERGY STAR Office Equipment program design and implementation. As a result, the EPA is now working with researchers and manufacturers to develop standard methods for testing and reporting typical (not worst-case) power consumption of new monitors in all power modes. When these procedures have been agreed upon, participating manufacturers will use them to generate reliable data, which EPA will use to establish criteria for the revised ENERGY STAR monitor specification.

\section{Personal Computers}

Current ENERGY STAR computer criteria specify sleep power according to the power supply's maximum continuous output rating, which, besides being difficult to determine, says nothing about actual power use. We suggest that revisions to the computer criteria be based on a more appropriate and identifiable metric.

When the data for all desktop computers in our sample was analyzed as a whole, the results indicate that actual desktop computer sleep power levels are far below even the lowest ENERGY STAR sleep criteria (based on the maximum continuous output rating of the computer's power supply), which therefore need to be revised downward if they are to apply only to the $25 \%$ most energy-efficient models on the market.

Half of the desktop computers in our sample exhibited a second, higher low-power level. To the extent that computers spend time in low-power levels other than the lowest (sleep) level, it may be worthwhile to specify a second, higher ENERGY STAR low-power level called, for example, light sleep. We do not, however, have an estimate of the percentage of time computers spend in intermediate low-power levels.

The range of off power consumption among desktop computers in our sample was small (1-4W), and does not suggest a need for an off power criteria for ENERGY STAR computers. Desktop on power consumption ranged widely, but appeared to be more closely associated with processor brand than with processor speed. We suggest that the trend toward increasing desktop computer on power be investigated with regard to minimizing computer on power without affecting functionality.

Integrated computer systems exist in a variety of configurations, but as yet are relatively few in number, although we can expect that to change. All three ICSs in our sample met the ENERGY STAR ICS criteria of $\leq 35 \mathrm{~W}$ in sleep, suggesting that the current criteria may eventually need to be revised downward. We suggest that more data needs to be collected on this category of computers as it continues to evolve.

By necessity and design, laptops are already much more energy-efficient than their desktop counterparts. However, because the power used by laptops includes that of the display as well as the computer processor, it is more appropriate to compare laptops to integrated computer systems. The 25th percentile of sleep power among laptops in our sample was $2 \mathrm{~W}$, compared to the ENERGY STAR ICS sleep criteria of $\leq 35 \mathrm{~W}$. We suggest laptops deserve further investigation, not as much in regard to reducing laptop power use as in applying laptop technology to minimizing the power used by desktops and integrated computer systems.

In summary, we propose continued metering of new personal computers, both to improve the size and robustness of the sample, and to identify and evaluate the factors that affect energy use in all power modes, with the goal of identifying savings opportunities and informing revisions to the ENERGY STAR criteria. 


\section{References}

Callwell, Chris, ECOS Consulting. 2002. Personal communication. July 8, 2002.

Callwell, Chris, and Travis Reeder. 2002. Recommended Approach to Revising Energy Star Monitor Specification and Summary of Process to Date. ECOS Consulting. Feb 15, 2002.

EPAct. 1992. Energy Policy Act of 1992. Conference Report 102-1018 to accompany H.R. 776. US Government Printing Office. Washington, DC: US House of Representatives. October 5th.

Groot, M. I., and P. J. S. Siderius. 2000. Monitors Statistical Analysis: on-mode power consumption. Delft, Netherlands: Van Holsteijn en Kemna BV, on behalf of Novem BV. April.

Kawamoto, Kaoru, J. Koomey, M. Ting, B. Nordman, R.E. Brown, M. Piette, A. Meier. 2001. Electricity Used by Office Equipment and Network Equipment in the U.S.: Detailed Report and Appendices. LBNL-45917. Lawrence Berkeley National Laboratory, Berkeley CA. February. Available at: http://enduse.lbl.gov/Projects/InfoTech.html

Nordman, Bruce, Alan Meier, and Don Aumann. 2002. "Even Electronics Deserve a Good Night's Sleep: Toward Standard Power User Interface Elements". In Proceedings of the 2002 ACEEE Summer Study on Energy Efficiency in Buildings (in press), American Council for an Energy Efficient Economy, Washington, DC

Nordman, Bruce, A. Meier, and M.A. Piette. 2000. PC and Monitor Night Status: Power Management Enabling and Manual Turn-off. LBNL-46099. Lawrence Berkeley National Lab, Berkeley, CA.

Nordman, Bruce, Mary Ann Piette, and Kris Kinney. 1996. Measured Energy Savings and Performance of Power-Managed Personal Computers and Monitors. LBL-38057. Lawrence Berkeley National Laboratory, Berkeley, CA. Available at: http://eetd.lbl.gov/EA/Reports/38057/

Nordman, Bruce, Mary Ann Piette, Kris Kinney, and Carrie Webber. 1997. User Guide to Power Management for PCs and Monitors. LBNL-39466. Lawrence Berkeley National Laboratory, Berkeley, CA. Available at: http://eetd.lbl.gov/EA/Reports/39466/

Roth, Kurt, Fred Goldstein, and Jonathan Kleinman. 2002. Energy Consumption by Office and Telecommunications Equipment in Commercial Buildings--Volume I: Energy Consumption Baseline. A.D. Little no. 72895-00. Prepared by Arthur D. Little for the U.S. Dept of Energy, Washington, DC. January. Available at: http://www.eren.doe.gov/buildings/documents

US EPA. 1999a. Computer Memorandum of Understanding (Version 3.0). U.S. Environmental Protection Agency, Climate Protection Partnerships Division, Washington, DC. July 1. Available at: http://estar4.energystar.gov/estar/ESPartnerLogos.nsf/PDF/Files/\$File/Computer.MOU.V3.pdf

US EPA. 1999b. Monitor Memorandum of Understanding (Version 3.0). U.S. Environmental Protection Agency, Climate Protection Partnerships Division. July 1. Available at: http://estar4.energystar.gov/estar/espartnerlogos.nsf/PDF/Files/\$File/Monitor.MOU.V3.pdf

US EPA. 2002a. Energy Star Labeled Computers and Monitors: Key Product Criteria [cited 2001]. Available at: http://www.epa.gov/nrgystar/purchasing/6a c\&m.html\#specs cm 
US EPA. 2002b. US EPA Global Warming Site [cited 2001]. Available at: http://www.epa.gov/globalwarming/

Webber, Carrie A., J.A. Roberson, R.E. Brown, C.T. Payne, B. Nordman, and J.G. Koomey. 2001. Field Surveys of Office Equipment Operating Patterns. LBNL-46930. Lawrence Berkeley National Laboratory, Berkeley, CA. September. Available at: http://enduse.lbl.gov/info/LBNL-46930.pdf 


\section{Appendix A: Metering Protocol}

\section{General (applies to all monitors and personal computers)}

After getting permission of the primary user or retailer, meter the equipment when it is not being used. Record the brand, model number, date of manufacture, and whether it exhibits an ENERGY STAR label (this information is usually found on a metal nameplate on the back or underside of the equipment). In a retail setting, record the price (with and without any discount); if in an office, inquire of its cost. For each piece of equipment, record the number of USB ports and any devices connected to them.

Record the power state in which the equipment is found, based on the power indicator, which is usually dark when off, green when on, and amber and/or blinking when in low power.

With the equipment on, record the PC operating system (OS) type and version (e.g., Windows 2000), as well as any automatic power management (PM) features and settings found in the OS control panel. Restore these settings when metering is complete. Record any unusual circumstances about the equipment or setup that could affect its power consumption or measurement.

Plug the power line meter (PLM) into an outlet and verify that the baseline power readout is zero watts; (if it isn't zero, subtract this measurement from subsequent measurements).

Now you are ready to measure on, off, and low-power levels, using the following guidelines. Whenever the equipment enters a new power level, wait at least 15 seconds for the reading to stabilize, then observe the readout for 30 seconds. Record the range and mode (most frequent number) to $0.1 \mathrm{~W}$.

For each low-power level measured, record the following:

- Whether the low-power level is activated automatically (via delay settings in the control panel) or manually (requiring that the user select the low-power level from a menu). Low-power levels that can be activated either manually or automatically (e.g., "Standby" in Windows) should be initiated and measured both ways.

- Appearance of the power indicator while the unit is in the low-power level (i.e., whether the light is green or amber, and whether it is flashing).

- The minimum level of action required to wake the unit up from its low-power level, tried in this sequence: mouse move, mouse click, keyboard action, or pushing a hard power button, and

- The measured time (in seconds) it takes the equipment to fully recover from the low-power level.

\section{Monitors}

In addition to the data described above, record actual screen size (measured diagonally) to the nearest inch, and the brand of desktop computer with which the monitor is being used.

If the monitor and computer are not already off, turn them both off. Plug the monitor into the PLM and measure monitor off power. Turn the monitor on and record monitor on power with the computer off. Turn the computer on; during boot-up record the OS and version. When boot-up is complete and the monitor displays the normal user-defined desktop, record monitor on power with the computer on.

In the power control panel, enable any PM options that are not already enabled (e.g., with the Windows 2000 OS, "Hibernate" is enabled via a checkbox). If you aren't sure whether a given low-power level affects the monitor, initiate the low-power level and measure monitor power consumption to find out. 
For each monitor low-power level, select the minimum delay setting (e.g. "1 min") so the monitor automatically enters that low-power level as soon as possible after cessation of user activity. Wait for the monitor to enter the low-power level and measure monitor power as described above. Record the appearance of the monitor power indicator, then initiate and record the wake event and recovery time.

After measuring each automatic low-power level, initiate and measure any manual low-power level(s) (e.g., in Windows, selecting "Suspend" from the "Start" menu). After measuring all power levels, monitor metering is complete. Restore as-found PM settings in the control panel. Turn the monitor off, unplug it from the PLM, and reconnect it to its power source.

\section{Personal Computers}

Record the data described above under General. If the PC is a laptop or ICS, record the actual screen size, measured diagonally, to the nearest inch. If it is an ICS, record the monitor type (CRT or LCD).

If the PC is not off, turn it off. If it is a laptop, the battery should be either fully charged, removed, or disconnected in order to prevent the power consumption measurements from including power used to recharge the battery. Plug the PC into the PLM and measure PC off power.

Turn the PC and monitor on. During boot-up, record the OS and version, CPU make and speed (in MHz), RAM size (in MB), and hard disk size (in GB). When the desktop is displayed, record on power.

In the power control panel, enable any PM options that are not already enabled (e.g., with the Windows 2000 OS, "Hibernate" is enabled via a checkbox). If you aren't sure whether a given low-power level affects the PC, initiate the low-power level and measure PC power consumption to find out.

For each PC low-power level, select the minimum time delay setting so the PC automatically enters that low-power level as soon as possible after cessation of user activity. Wait for the PC to enter the low-power level and measure PC power consumption as described above under General. Record the appearance of the PC power indicator, then initiate and record the wake event and recovery time. Also record if the PC does not enter a low-power level after the specified time. As with monitors, low-power levels that can be induced manually or automatically (e.g., "Suspend" in Windows 2000) should be initiated and measured both ways.

After measuring each automatic PC low-power level, initiate and measure any manual low-power level (e.g., "Suspend" from the "Start" menu). After measuring all power levels, PC metering is complete. Restore the as-found PM settings in the control panel. Turn the PC off, unplug it from the PLM, and reconnect it to its power source. 
Appendix B: Metering Results (Blank fields either do not apply or are not available.)

Table B-1. Monitor Metering Results, Sorted by Monitor Type \& Size

\begin{tabular}{|c|c|c|c|c|c|c|c|c|c|c|c|c|}
\hline $\begin{array}{l}\text { Monitor } \\
\text { ID No. }\end{array}$ & $\begin{array}{l}\text { Mfr Date } \\
(* \text { estimate })\end{array}$ & Cost/Price $\$$ & Type & $\begin{array}{l}\text { Size } \\
\text { (in) }\end{array}$ & $\begin{array}{l}\text { Monitor Off } \\
\text { (W), PC Off }\end{array}$ & $\begin{array}{l}\text { Monitor On } \\
\text { (W), PC Off }\end{array}$ & $\begin{array}{l}\text { Monitor On } \\
\text { (W), PC On }\end{array}$ & Sleep $(\mathrm{W})$ & $\begin{array}{l}\text { Wake from } \\
\text { Sleep }(\mathrm{sec})\end{array}$ & $\begin{array}{l}\text { Deep Sleep } \\
\text { (W) }\end{array}$ & $\begin{array}{l}\text { Wake from Deep } \\
\text { Sleep }(\mathrm{sec})\end{array}$ & Computer OS \\
\hline 7 & 2000-Nov & & CRT & 15 & 3 & & 54 & & & 3 & 8 & Windows ME \\
\hline 11 & 2000-Nov & 200 & CRT & 15 & 0 & 2 & 48 & & & 2 & 8 & Windows 98 \\
\hline 14 & 2001-Apr & & CRT & 15 & 0 & 3 & 72 & & & 3 & 7 & Windows 00 \\
\hline 15 & 2001-Feb & & CRT & 15 & 0 & 1 & 56 & & & 1 & 5 & Windows 98 \\
\hline 16 & 2001-Jun & & CRT & 17 & 0 & 2 & 57 & & & 2 & & Windows 98 \\
\hline 20 & 2001-Jun* & & CRT & 17 & 0 & 1 & 76 & & & & & Windows NT \\
\hline 22 & 2000-Nov & & CRT & 17 & 0 & 1 & 55 & & & 1 & 5 & Windows 00 \\
\hline 27 & 2000-Oct & 400 & CRT & 17 & 1 & 1 & 60 & & & 1 & 5 & Windows XP \\
\hline 29 & 2000-Nov & 450 & CRT & 17 & 3 & 3 & 58 & 6 & 2 & 3 & 10 & Windows XP \\
\hline 9 & 2001-Jan & 270 & CRT & 19 & 9 & & 85 & 69 & 4 & 61 & 8 & Windows ME \\
\hline 10 & 2001-Jan & 300 & CRT & 19 & 0 & & 71 & & & 2 & 8 & Windows ME \\
\hline 13 & 2001-May & & CRT & 19 & 0 & 74 & 90 & & & 2 & 11 & Windows 98 \\
\hline 26 & 2001-Jun & & CRT & 19 & 0 & 1 & 86 & & & 2 & 8 & Windows 00 \\
\hline 30 & 2001-Jan & 500 & CRT & 19 & 0 & 1 & 92 & & & 2 & 6 & Windows XP \\
\hline 33 & 2001-Apr & 450 & CRT & 19 & 2 & 2 & 70 & 9 & 1 & 2 & 12 & Windows XP \\
\hline 6 & 2000-Jul & & CRT & 21 & 2 & 2 & 110 & & & 2 & 8 & Windows 98 \\
\hline 12 & 2001-Mar & 1,000 & CRT & 21 & 0 & 78 & 99 & 79 & 2 & 28 & 1 & Windows ME \\
\hline 23 & 2000-Oct & & CRT & 21 & 0 & 2 & 101 & & & 2 & 8 & Windows 00 \\
\hline 25 & 2001-Oct & & CRT & 21 & 0 & 75 & 96 & & & 1 & 3 & Windows 00 \\
\hline 1 & 2000-Jul* & & LCD & 15 & 2 & 2 & 33 & 10 & & 2 & 3 & Windows 00 \\
\hline 2 & 2001-Mar & & LCD & 15 & 2 & & 18 & & & 2 & & Windows 00 \\
\hline 5 & 2001-Apr & & LCD & 15 & 2 & & 17 & & & 2 & & Windows 00 \\
\hline 8 & 2001-Jun & 450 & LCD & 15 & 3 & 24 & 24 & & & 1 & 3 & Windows ME \\
\hline 17 & 2001-Aug & & LCD & 15 & 2 & 2 & 19 & & & 2 & 1 & Windows 98 \\
\hline 21 & 2001-Mar & & LCD & 15 & 4 & 3 & 16 & & & 3 & 1 & Windows 98 \\
\hline 31 & 2001-Aug & & LCD & 15 & 1 & 2 & 22 & & & 2 & 3 & Windows XP \\
\hline 32 & 2001-Sep & 650 & LCD & 15 & 2 & 2 & 15 & & & 2 & 1 & Windows XP \\
\hline 35 & 2001-Oct* & 380 & LCD & 15 & 1 & 1 & 14 & & & 1 & 2 & Mac OS 8.6 \\
\hline 18 & 2001-Jul & 920 & LCD & 17 & 0 & 36 & 38 & & & 2 & 1 & Windows 00 \\
\hline 24 & 2001-Aug & & LCD & 17 & 3 & 4 & 34 & & & 3 & 3 & Windows 98 \\
\hline 28 & 2001-Jul* & 900 & LCD & 17 & 1 & 2 & 36 & & & 2 & 2 & Windows XP \\
\hline 34 & 2001-Oct & 750 & LCD & 17 & 2 & 2 & 33 & & & 2 & 3 & Windows 00 \\
\hline 3 & 2000-Nov & & LCD & 18 & 1 & & 59 & & & 2 & & Mac OS 9.1 \\
\hline 4 & 2000-Nov* & & LCD & 18 & 4 & & 63 & 9 & & 4 & & Mac OS 8.1 \\
\hline 19 & 2001-Sep & & LCD & 18 & 0 & 2 & 39 & & & 2 & 2 & Windows 00 \\
\hline
\end{tabular}


Appendix B: Metering Results (Cont.) (Blank fields do not apply or are not available)

Table B-2. Desktop Computer Metering Results (Sorted by On Power)

\begin{tabular}{|c|c|c|c|c|c|c|c|c|c|c|c|c|}
\hline $\begin{array}{l}\text { PC ID } \\
\text { No. }\end{array}$ & $\begin{array}{l}\text { Mfr Date } \\
\text { (*estimate) }\end{array}$ & $\begin{array}{c}\text { Cost/ } \\
\text { Price \$ }\end{array}$ & Type & $\begin{array}{l}\text { CPU Make, } \\
\text { Version }\end{array}$ & $\begin{array}{l}\text { CPU speed } \\
\text { (MHz) }\end{array}$ & $\begin{array}{l}\text { Off } \\
\text { (W) }\end{array}$ & $\begin{array}{l}\text { On } \\
\text { (W) }\end{array}$ & $\begin{array}{l}\text { Light Sleep } \\
\text { (W) }\end{array}$ & $\begin{array}{l}\text { Wake from Light } \\
\text { Sleep }(\mathrm{sec})\end{array}$ & Sleep $(\mathrm{W})$ & $\begin{array}{l}\text { Wake from } \\
\text { Sleep }(\mathrm{sec})\end{array}$ & Computer OS \\
\hline 7 & 2001-Jul* & & desktop & Intel P3 & 733 & 2 & 28 & & & 20 & 5 & Windows 98 \\
\hline 2 & 2000-Sep & 1,650 & desktop & Intel P3 & 733 & 4 & 36 & 29 & 6 & 24 & 12 & Windows 98 \\
\hline 6 & 2001-Jul* & & desktop & Intel P3 & 1000 & 2 & 43 & & & 3 & 14 & Windows 2000 \\
\hline 8 & 2001-Jun* & 1,400 & desktop & Intel P3 & 1000 & 4 & 47 & 36 & 3 & 5 & 14 & Windows 98 \\
\hline 12 & 2001-Jul* & 1,200 & desktop & Intel P4 & 1700 & 2 & 59 & 52 & 6 & 2 & 16 & Windows XP \\
\hline 14 & 2001-Jul* & 1,200 & desktop & Intel P4 & 1700 & 1 & 60 & & & 2 & 14 & Windows XP \\
\hline 1 & 2001-Jun & 1,900 & desktop & Intel P4 & 1300 & 4 & 63 & & & 4 & & Windows 2000 \\
\hline 11 & 2001-Aug & & desktop & Intel P4 & 1800 & 2 & 63 & 54 & 3 & 3 & 9 & Windows XP \\
\hline 4 & 2001-May & & desktop & Intel P4 & 1300 & 3 & 65 & 53 & 11 & 5 & 24 & Windows 98 \\
\hline 13 & 2001-Jul* & 750 & desktop & AMD Athlon & 1300 & 3 & 93 & 32 & 2 & 3 & 12 & Windows XP \\
\hline 9 & 2001-Oct & & desktop & Intel P4 & 1800 & 3 & 94 & 90 & 4 & 4 & 10 & Windows 2000 \\
\hline 3 & 2001-Jun & 1,430 & desktop & AMD Athlon & 1000 & 4 & 101 & & & 4 & 8 & Windows 2000 \\
\hline 5 & 2001-Jun & & desktop & AMD Athlon & 1400 & 2 & 105 & & & 48 & 8 & Windows ME \\
\hline 10 & 2001-Oct & 1,800 & desktop & AMD Athlon & 1400 & 4 & 117 & & & 5 & 19 & Windows 2000 \\
\hline
\end{tabular}

Table B-3. Laptop Computer Metering Results (Sorted by On Power)

\begin{tabular}{|c|c|c|c|c|c|c|c|c|c|c|c|c|}
\hline $\begin{array}{l}\text { Laptop } \\
\text { ID No. }\end{array}$ & $\begin{array}{l}\text { Mfr Date } \\
(* \text { estimate })\end{array}$ & $\begin{array}{c}\text { Cost/ } \\
\text { Price } \$\end{array}$ & Type & $\begin{array}{l}\text { CPU Make, } \\
\text { Version }\end{array}$ & $\begin{array}{l}\text { CPU speed } \\
(\mathrm{MHz})\end{array}$ & $\begin{array}{l}\text { Off } \\
\text { (W) }\end{array}$ & $\begin{array}{l}\text { On } \\
\text { (W) }\end{array}$ & $\begin{array}{l}\text { Light Sleep } \\
\text { (W) }\end{array}$ & $\begin{array}{l}\text { Wake from Light } \\
\text { Sleep }(\mathrm{sec})\end{array}$ & Sleep $(\mathrm{W})$ & $\begin{array}{l}\text { Wake from } \\
\text { Sleep }(\mathrm{sec})\end{array}$ & Computer OS \\
\hline 3 & $2000-O c t^{*}$ & 1,800 & Laptop & Celeron & 600 & 1 & 14 & 6 & 2 & 4 & 4 & Windows 2000 \\
\hline 7 & 2000-Aug* & 1,990 & Laptop & Celeron & & 1 & 14 & 8 & 1 & 1 & & Windows 98 \\
\hline 9 & 2000-Jun* & 1,800 & Laptop & Intel P2 & & 2 & 15 & 18 & 1 & 2 & 16 & Windows 98 \\
\hline 4 & 2001-Jul* & 2,070 & Laptop & Mac G4 & 400 & 2 & 17 & 10 & 1 & 2 & 2 & Mac OS X \\
\hline 2 & 2001-Mar* & 2,500 & Laptop & Intel P3 & 600 & 2 & 19 & 12 & 1 & 3 & 14 & Windows 2000 \\
\hline 6 & 2001-Jul* & 1,200 & Laptop & Celeron & 800 & 1 & 19 & 2 & 4 & 1 & 15 & Windows 98 \\
\hline 1 & 2001-Mar* & 2,700 & Laptop & & & 2 & 20 & 12 & & 3 & & Windows 2000 \\
\hline 5 & 2001-Jul* & 2,190 & Laptop & Intel P3 & 900 & 3 & 25 & & & 3 & 16 & Windows 98 \\
\hline 8 & 2001-Jun* & 3,130 & Laptop & Intel P3 & 1000 & 1 & 25 & 19 & 1 & 8 & 6 & Windows 2000 \\
\hline
\end{tabular}

Table B-4. Integrated Computer System Metering Results (Sorted by On Power)

\begin{tabular}{|c|c|c|c|c|c|c|c|c|c|c|c|c|}
\hline $\begin{array}{l}\text { ICS ID } \\
\text { No. }\end{array}$ & $\begin{array}{l}\text { Mfr Date } \\
\text { (*estimate) }\end{array}$ & $\begin{array}{c}\text { Cost/ } \\
\text { Price } \$\end{array}$ & Type & $\begin{array}{l}\text { CPU Make, } \\
\text { Version }\end{array}$ & $\begin{array}{l}\text { CPU speed } \\
(\mathrm{MHz})\end{array}$ & $\begin{array}{l}\text { Off } \\
\text { (W) }\end{array}$ & $\begin{array}{l}\text { On } \\
\text { (W) }\end{array}$ & $\begin{array}{l}\text { Light Sleep } \\
\text { (W) }\end{array}$ & $\begin{array}{l}\text { Wake from Light } \\
\text { Sleep }(\mathrm{sec})\end{array}$ & Sleep $(\mathrm{W})$ & $\begin{array}{l}\text { Wake from } \\
\text { Sleep }(\mathrm{sec})\end{array}$ & Computer OS \\
\hline 1 & 2001-Jul* & 1,900 & integral PC-LCD & Intel P3 & 867 & 6 & 54 & 24 & 1 & 16 & 14 & Windows ME \\
\hline 3 & 2001-Jul* & 950 & integral PC-CRT & Mac G3 & 600 & 4 & 88 & 78 & 1 & 31 & 16 & Mac OS 9.2 \\
\hline 2 & 2001-Aug & 3,310 & power-linked PC-LCD & Mac G4 & 867 & 8 & 131 & 102 & 4 & 10 & 7 & Mac OS X \\
\hline
\end{tabular}




\section{Appendix C: Statistical Analysis of Monitor Power Levels, by Type \& Size}

Table C1. Monitor Off Power (W), by Monitor Type \& Size

\begin{tabular}{|c|ccccc|cccc|}
\hline $\begin{array}{c}\text { Type } \\
\text { Size }\end{array}$ & All & 15" & $\begin{array}{c}\text { CRT } \\
\text { 17" }\end{array}$ & 19" & 21" & All & 15" & 17" & 18" \\
\hline Count & 19 & 4 & 5 & 5 & 5 & 16 & 9 & 4 & 3 \\
\hline \multicolumn{8}{|c|}{ Monitor Off Power (W), with PC Off } \\
\hline Min & 0 & 0 & 0 & 0 & 0 & 0 & 1 & 0 & 0 \\
Max & 9 & 3 & 3 & 9 & 2 & 4 & 4 & 3 & 4 \\
Average/Mean & 1 & 1 & 1 & 2 & 1 & 2 & 2 & 2 & 2 \\
25th percentile & 0 & 0 & 0 & 0 & 0 & 1 & 2 & 1 & 1 \\
Median & 0 & 0 & 0 & 0 & 0 & 2 & 2 & 2 & 1 \\
75th percentile & 2 & 1 & 1 & 0 & 2 & 2 & 2 & 2 & 3 \\
\hline
\end{tabular}

Table C2. Monitor On Power (with PC Off), by Monitor Type \& Size

\begin{tabular}{|c|c|c|c|c|c|c|c|c|c|}
\hline Type & \multicolumn{5}{|c|}{ CRT } & \multicolumn{4}{|c|}{ LCD } \\
\hline Size & All & $15 "$ & $17 "$ & $19^{\prime \prime}$ & $21 "$ & All & $15^{\prime \prime}$ & $17^{\prime \prime}$ & $18 "$ \\
\hline Count & 16 & 3 & 5 & 3 & 5 & 12 & 7 & 4 & 1 \\
\hline \multicolumn{10}{|c|}{ Monitor On Power (W), with PC Off } \\
\hline Min & 1 & 1 & 1 & 1 & 2 & 1 & 1 & 2 & 2 \\
\hline Max & 78 & 3 & 3 & 74 & 78 & 36 & 24 & 36 & 2 \\
\hline Average/Mean & 16 & 2 & 2 & 25 & 32 & 7 & 5 & 11 & 2 \\
\hline 25th percentile & 1 & 2 & 1 & 1 & 2 & 2 & 2 & 2 & 2 \\
\hline Median & 2 & 2 & 1 & 1 & 2 & 2 & 2 & 3 & 2 \\
\hline 75th percentile & 3 & 3 & 2 & 38 & 75 & 3 & 3 & 12 & 2 \\
\hline
\end{tabular}

Table C3. Monitor On Power (with PC On), by Monitor Type \& Size

\begin{tabular}{|c|ccccc|cccc|}
\hline $\begin{array}{c}\text { Type } \\
\text { Size }\end{array}$ & All & $15 "$ & $\begin{array}{c}\text { CRT } \\
17^{\prime \prime}\end{array}$ & $19^{\prime \prime}$ & $21^{\prime \prime}$ & All & $15^{\prime \prime}$ & LCD & 17" \\
\hline Count & 19 & 4 & 5 & 5 & 5 & 16 & 9 & 4 & 3 \\
\hline \multicolumn{8}{|c}{ Monitor On Power (W), with PC On } \\
\hline Min & 48 & 48 & 55 & 71 & 70 & 14 & 14 & 33 & 39 \\
Max & 110 & 72 & 76 & 92 & 110 & 63 & 33 & 38 & 63 \\
Average/Mean & 76 & 58 & 61 & 85 & 95 & 30 & 20 & 35 & 54 \\
25th percentile & 58 & 53 & 57 & 85 & 96 & 18 & 16 & 34 & 49 \\
Median & 72 & 55 & 58 & 86 & 99 & 29 & 18 & 35 & 59 \\
75th percentile & 91 & 60 & 60 & 90 & 101 & 37 & 22 & 37 & 61 \\
\hline
\end{tabular}

Table C4. Monitor Deep Sleep Power, by Monitor Type \& Size

\begin{tabular}{|c|c|c|c|c|c|c|c|c|c|}
\hline Type & \multicolumn{5}{|c|}{ CRT } & \multicolumn{4}{|c|}{ LCD } \\
\hline Size & All & $15 "$ & $17 "$ & $19 "$ & $21 "$ & All & $15 "$ & $17 "$ & $18 "$ \\
\hline Count & 18 & 4 & 4 & 5 & 5 & 16 & 9 & 4 & 3 \\
\hline \multicolumn{10}{|c|}{ Monitor Deep Sleep Power (W) } \\
\hline Min & 1 & $\overline{1}$ & 1 & 2 & 1 & $\overline{1}$ & 1 & 2 & 2 \\
\hline Max & 61 & 3 & 3 & 61 & 28 & 4 & 3 & 3 & 4 \\
\hline Average/Mean & 7 & 2 & 2 & 14 & 7 & 2 & 2 & 2 & 3 \\
\hline 25th percentile & 2 & 2 & 1 & 2 & 2 & 2 & 2 & 2 & 2 \\
\hline Median & 2 & 3 & 2 & 2 & 2 & 2 & 2 & 2 & 2 \\
\hline 75th percentile & 3 & 3 & 2 & 2 & 2 & 2 & 2 & 2 & 3 \\
\hline
\end{tabular}

